OPEN ACCESS

Edited by: Carlos Francisco De Sousa Reis, University of Coimbra, Portugal

Reviewed by: Sheila Keener, Old Dominion University, United States Onintze Lopez De Letona University of Deusto, Spain

*Correspondence: Julia Aubouin-Bonnaventure juliaaubouin@hotmail.fr

Specialty section:

This article was submitted to Organizational Psychology, a section of the journal

Frontiers in Psychology

Received: 14 June 2021 Accepted: 10 September 2021 Published: 13 October 2021

Citation

Aubouin-Bonnaventure $J$ Fouquereau E, Coillot H, Lahiani FJ and Chevalier S (2021) Virtuous Organizational Practices: A New

Construct and a New Inventory.

Front. Psychol. 12:724956 doi: 10.3389/fpsyg.2021.724956

\section{Virtuous Organizational Practices: A New Construct and a New Inventory}

\author{
Julia Aubouin-Bonnaventure ${ }^{1 *}$, Evelyne Fouquereau ${ }^{1}$, Hélène Coillot ${ }^{1}$, \\ Fadi Joseph Lahiani ${ }^{2}$ and Séverine Chevalier ${ }^{1}$ \\ ${ }^{1}$ QualiPsy EE 1901, Psychology Department, University of Tours, Tours, France, ${ }^{2}$ AD CONSEIL, Malakoff, France
}

Research on the identification of organizational practices that promote individual and organizational performance is now very extensive. However, several studies have revealed the dark side of these practices on employees' psychological health. Consequently, researchers have called on the scientific community to focus on the well-being of workers and to identify the organizational practices that promote it. Thus, the aim of the present research was to fill this gap by introducing a new conceptualization of organizational practices supporting the psychological health of employees and proposing a new improved measure to assess them. Drawing on the American Psychological Association's model of Psychologically healthy workplace, we first conceptualized the innovative multidimensional construct of virtuous organizational practices. We then conducted four studies $(N=1,407)$ to develop and validate the Virtuous Organizational Practices inventory. Results of exploratory statistical analyses provide strong evidence of the second-order factor structure of the inventory in different French samples and of the convergent, predictive and incremental validity of this tool. Implications for researchers, organizations and practitioners and avenues for future research are discussed.

Keywords: organizational virtuousness, virtuous organizational practices, virtuous organizational practices inventory, VOPi, scale, psychological health, well-being

\section{INTRODUCTION}

Since the 1990s, research on organizational practices that promote workers' performance and commitment has aroused growing interest in the scientific community (Wang et al., 2020). For example, Murphy et al. (2018) recently carried out a literature review on this subject and identified a preliminary database of nearly 16,000 publications between 1991 and 2015. This vast field of scientific research currently includes many constructs (e.g., High-performance work system, High-involvement work system, High-commitment work system, Human resources practices, and Strategic human resources management). Because the practices are chosen on empirical rather than conceptual grounds, researchers have difficulty agreeing on the number and nature of practices to be considered (Mendelson et al., 2011; Boon et al., 2019). Nevertheless, numerous studies have shown that these organizational practices are related to improved individual performance, including task performance and organizational citizenship behavior (e.g., Boon et al., 2011; Zhang et al., 2018) and to organizational efficiency, including work unit productivity, financial outcomes (e.g., sales growth, return on invested capital), product/service quality and customer satisfaction, and also to a decrease in labor costs, absenteeism, voluntary turnover, and hospital mortality rates 
(Combs et al., 2006; West et al., 2006; Guthrie et al., 2009; Jiang et al., 2012; Raineri, 2017; Saridakis et al., 2017; Schmidt and Pohler, 2018).

As underlined by some authors, the effects of these organizational practices on workers' psychological health are only a secondary concern (Guest, 2017), the employees' psychological health being considered only as a means to optimize their performance. Moreover, while several studies have shown that these organizational practices have positive relationships with some positive outcomes in terms of workers' health (e.g., job satisfaction, affective commitment: Kooij et al., 2010; Domínguez-Falcón et al., 2016), some authors observe that it is too early to consider that these necessarily improve well-being (Zhang et al., 2013). Indeed, some research has revealed the "dark side" of these organizational practices (Han et al., 2020); for example, several studies have concluded that they degrade employees' working conditions by increasing job demands, such as heavier workloads and more demands of service quality (Ramsay et al., 2000; Jensen et al., 2013; Avgoustaki, 2015; Oppenauer and Van De Voorde, 2016; Wang et al., 2019). Kroon et al. (2009) found a positive relationship between highperformance work and burnout, which was fully mediated by job demands, and Oppenauer and Van De Voorde (2016) observed that these practices were positively linked to work overload, which was significantly related to emotional exhaustion. Other studies have underlined the direct harmful effects of these organizational practices on workers' psychological health, such as an increase in work-life interference, anxiety, perceived stress, burnout and turnover intentions (Godard, 2001; Wood and de Menezes, 2011; Jensen et al., 2013; Topcic et al., 2016).

According to some researchers, these results indicate that organizational practices leading to increased performance are not necessarily the same as those leading to employees' psychological well-being (e.g., Guest, 2017; Loon et al., 2018). Consequently, they stress the importance of identifying organizational practices that promote employees' health. Some work in this direction has recently emerged (Guest, 2017; Cooper et al., 2019; Huettermann and Bruch, 2019; Salas-Vallina et al., 2021), but with several important limitations. First, there is significant conceptual confusion in this research area, notably between formal and informal practices, or organizational and managerial practices (Guest, 2017; Cooper et al., 2019; Salas-Vallina et al., 2021). Secondly, most studies have examined these practices from the perspective of senior executives and HR actors (Huettermann and Bruch, 2019), while it has been clearly demonstrated that the workers' perception of organizational practices is the best predictor of their health, attitudes and behaviors at work (Edgar and Geare, 2005). Thirdly, while the measured constructs have been given new names (e.g., wellbeing-oriented human resource management practices, health-related HRM), the tools used to assess them are the same as those used to measure organizational practices propitious to individual performance (Cooper et al., 2019). In other words, to our knowledge, there is currently no specific validated scale measuring workers' perceptions of formal organizational practices that promote their psychological health. Finally, although there are numerous studies about organizational practices that promote employees' well-being, they over-simplify these practices because they do not measure their combined effect (Kooij et al., 2010; Butts et al., 2013). Thus, no integrative psychological construct currently exists in this research domain, and there is a real lack of accurate measures to improve the understanding of the effects of organizational practices specifically focused on workers' wellbeing and professional quality of life.

\section{The Present Research}

First, this research aimed to develop a new integrative psychological construct of organizational practices promoting employees' psychological well-being. Based on the concept of organizational virtuousness and the model of Psychologically healthy workplace developed by the American Psychological Association (APA), this paper presents the construct of Virtuous Organizational Practices (VOP). The second aim was to create and validate a new scale (i.e., Virtuous Organizational Practices inventory, VOPi) to assess these practices. To this end, we conducted four studies involving a total of 1,407 French workers from various sectors (e.g., private, public, and non-profit organizations). The purpose of the first study was to generate a pool of items constituting the framework of the VOPi for subsequent testing. The second and third studies tested the VOPi's factor structure through exploratory and confirmatory factor analyses. In the fourth study, we tested the predictive, convergent and incremental validity of the VOPi.

\section{Virtuous Organizational Practices}

As mentioned above, the first aim of the present study was to contribute to research on the organizational practices promoting workers' well-being by developing a new integrative conceptual approach, based on the concept of organizational virtuousness derived from positive psychology and the APA model of Psychologically healthy workplace. The concept of organizational virtuousness (Meyer, 2018) emerged from the field of positive organizational scholarship. Broadly speaking, virtuousness means "excellence" and refers to the pursuit of human flourishing (Cameron et al., 2003; Bright et al., 2006). Bright et al. (2006) made a distinction between virtuousness in the organization, which refers to "the behavior of individuals in organizational settings that helps people flourish as human beings" (p. 252) and virtuousness through organization, which is the ability of an organization to support virtuous activities among its members (Cameron et al., 2004; Cameron, 2008; Spreitzer et al., 2012) through organizational characteristics such as attributes, structure, systems and processes that promote the optimal functioning of employees (Cameron et al., 2003; Cameron and Caza, 2004; Nikandrou and Tsachouridi, 2015; Sison and Ferrero, 2015). In line with this conceptual framework, the new integrative construct of VOP presented here is defined as formal organizational practices that focus on employees' psychological well-being and optimal health. VOP differ from commonly defined organizational practices (e.g., High-performance work system, high-commitment work system, and Strategic human resources management) because they prioritize workers' well-being over their performance goals. The organizational practices included in this new construct 
were identified through: (1) the APA's empirical model of Psychologically healthy workplace, and (2) an in-depth review of the scientific literature on the organizational practices that are commonly associated with well-being at work.

The APA's Psychologically healthy workplace program has significant international influence. It was initiated in 1999 to recognize and support organizations fostering the health and well-being of their employees through practices, programs and policies that could thus be considered as virtuous practices. This model highlights five "virtuous" organizational practices:

1. Practices of Participative Decision-Making (PPDM), also associated with organizational democracy, refer to "ongoing, broad-based, and institutionalized employee participation that is not ad hoc or occasional in nature" (Weber et al., 2020, p. 1009). These practices are numerous and include decision-making meetings, problem-solving groups, formal suggestion systems (e.g., suggestion boxes), referendums, opinion surveys, and worker-supervisor meetings to determine goals and work methods (Lavelle et al., 2010; Wilkinson et al., 2010; Marchington, 2015). Numerous studies have demonstrated that these practices are positively associated with positive emotions, job satisfaction, affective commitment and organizational commitment, and negatively related to negative emotions (e.g., Witt et al., 2000; Kooij et al., 2010; Mendelson et al., 2011; Ogbonnaya et al., 2017). They allow employees to exercise control over their professional environment and offer an essential resource for escaping from stressful situations (Probst, 2005). More precisely, PPDM provide opportunities for workers to gain more information, to better understand organizational processes, be engaged in problem-solving and to influence organizational choices by expressing their thoughts, opinions and ideas and defending their interests (Bogler and Somech, 2005; Somech, 2010). Finally, PPDM show employees that they are valued by their superior and their organization (Yoerger et al., 2015; Weber et al., 2020).

2. Work-Life Balance Practices (WLBP) refer to "discretionary and formal organizational policies, services, and benefits aimed at reducing employees' work-family conflict and/or supporting their family roles outside the workplace" (Masterson et al., 2021, p. 118). The metaanalysis of 57 studies by Butts et al. (2013) confirmed that WLBP are positively related to job satisfaction, affective commitment and intention to stay, and negatively related to work-family conflict. They enable employees to choose their working hours (e.g., flextime, compressed workweek), working time (e.g., part-time) as well as the work location (e.g., telecommuting; Hill et al., 2008; Bae and Goodman, 2014). They also provide instrumental support through financial assistance, child-care services and elder-care assistance (Bae and Goodman, 2014). They thus help workers to be more flexible in carrying out their work in order to meet their professional and personal requirements (Jahn et al., 2003; Cogin et al., 2017).
3. Health and Safety Practices (HSP) are those that promote employee health and safety within the organization (Mearns et al., 2010; Huang et al., 2013; Parker et al., 2017; Schulz et al., 2017). They differ from the concept of psychosocial safety climate (PSC) in that they consider the overall health (i.e., psychological, physical) of employees and not just their psychological health (Hall et al., 2010). These practices are related positively with job satisfaction, work engagement and well-being and negatively with emotional exhaustion and psychological distress (e.g., Grawitch et al., 2007; Nielsen et al., 2011; Gragnano et al., 2017). Their aim is to create a safe professional environment and to reduce psychosocial risks, accidents and injuries in the workplace (Christian et al., 2009; Dollard and Bakker, 2010; Nahrgang et al., 2011; Dollard et al., 2012). They show employees that management values and prioritizes their well-being over performance goals (Hall et al., 2010). Interestingly, while the APA model considers "Health and Safety" as a single dimension, several authors recommend that they should be studied as two separate constructs (Mearns et al., 2010; Zweber et al., 2016; Parker et al., 2017).

4. Recognition Practices (RP) are those that give employees feedback on their work and reward them for their contribution to the organization and their professional achievements (Fallon and Rice, 2015). RP are numerous, and include bonuses, promotion, congratulations, awards, and improving working conditions (Brun and Dugas, 2005; Fall, 2015). They can be classified according to their purpose, namely: recognition-relationship (i.e., practices showing employees that they are valued as individuals), recognition-reward (i.e., practices recognizing an outcome), and recognition-accomplishment (i.e., practices that give the employee a sense of purpose; Roche, 2014). RP promote the development of self-confidence and self-esteem (El Akremi et al., 2009; Fallon and Rice, 2015) and are positively associated with well-being indicators such as job satisfaction, affective commitment and intrinsic motivation (e.g., Kooij et al., 2010; Fall, 2015). They also have negative relationships with job stress, fatigue, emotional exhaustion, work-life imbalance and turnover intention (e.g., Grawitch et al., 2007; Boxall and Macky, 2014). Some authors advocate combining different types of RP (e.g., feedback on work, monetary recognition, and social recognition), which has been shown to have a greater positive effect on behavior (e.g., task performance) than each reward practice considered in isolation (Stajkovic and Luthans, 2003).

5. Practices of Career Management (PCM), also called "growth and development," are defined as "programs, processes, and other forms of assistance provided by organizations to support and enhance their employees' career success" (Kong et al., 2011, p. 112). They include training programs, career counseling, formal mentoring, internal mobility, outplacement, and preretirement programs (Bagdadli and Gianecchini, 2019). Numerous studies have demonstrated that PCM are 
positively related to job satisfaction, affective commitment, well-being and intention to remain (e.g., ArmstrongStassen and Ursel, 2009; Rego and Cunha, 2009; Kooij et al., 2010) and negatively associated with emotional exhaustion and turnover intention (Grawitch et al., 2007). Indeed, PCM have substantial value for workers by helping them develop their knowledge and skills and use them in new situations (Grawitch et al., 2007), challenging them, stimulating them to expand their potential, and supporting their employability (Armstrong-Stassen and Stassen, 2013). They are also a sign that the organization values them and is prepared to make long-term investment in their career (Paré and Tremblay, 2007). Finally, these practices make it possible to match the employees' interests, aspirations, and abilities with organizational opportunities.

Finally, communication is the foundation for all psychologically healthy workplace practices, by showing workers that the organization recognizes their existence. Also referred to as "sharing information," Communication Practices (CP) are "a set of practices set up by organizations to disseminate and receive information" (Tremblay et al., 2000, p. 4). Several studies have observed that $\mathrm{CP}$ have positive relationships with job satisfaction and affective commitment, and negative relationships with job stress, fatigue and work-life imbalance (e.g., Kooij et al., 2010; Mendelson et al., 2011; Boxall and Macky, 2014). Indeed, CP allow workers to understand what the organization expects of them regarding their role, goals, and tasks (Tremblay et al., 2000; van Vuuren et al., 2007). Furthermore, by receiving the right information at the right time, workers are able to understand and predict organizational plans and can adapt their behavior accordingly (Lages et al., 2005). Finally, the transmission of accurate information promotes the development of a climate of trust and mutual respect (Sousa-Lima et al., 2013). Finally, these practices can also be a signal that the organization cares about the well-being, concerns and opinions of workers (Zhang and Agarwal, 2009).

In brief, this model focuses on the formal practices that organizations can implement and optimize in order to promote their employees' psychological health. However, it does not include two other organizational practices that have been shown to have positive effects on employees' health, namely, Organizational Justice Practices (OJP) and Social Dialogue Practices (SDP).

Many scientists have argued that organizational justice is an important factor of workers' health. More precisely, in the early 2000s, procedural and distributive equity (Wilson et al., 2004) as well as the broader notion of fairness (Kelloway and Day, 2005) were identified as features of "healthy" work environments. More recently, Guest (2017) added equal opportunities and fair rewards in his descriptive model of practices promoting the psychological health of employees. Several meta-analyses have also reported the beneficial nature of organizational justice on employees' well-being, with positive relationships with job satisfaction, organizational commitment and positive emotions, and negative relationships with negative emotions, withdrawal and counterproductive work behavior (Colquitt et al., 2001,
2013). Moreover, no study has shown any deleterious effect of these practices on the psychological health of employees. OJP show workers that the organization respects them, cares about their well-being, supports them and values them (Le et al., 2018). For this reason, we considered that they should be included in our new VOP construct. OJP include fair compensation (e.g., wages, bonuses, and promotions; Adams, 1965), formalization of compensation criteria (e.g., transparent salary policy, merit pay, communication of criteria for awarding bonuses; Thibaut and Walker, 1975), equitable transmission of information (e.g., information meeting; Greenberg, 1993) as well as fair treatment (e.g., equal opportunity program, program to prevent discrimination at work; Colquitt, 2001).

Similarly, several empirical studies have provided evidence that SDP, also called social collective bargaining, joint consultation or industrial relations climate, are positively associated with indicators of well-being such as job satisfaction, organizational commitment, and work-life balance (e.g., Deery and Iverson, 2005; Conway and Monks, 2008; Snape and Redman, 2012; De Prins et al., 2018). These practices give workers the opportunity to express themselves and protect their interests (Deery et al., 2014). They also improve the clarity of mutual objectives, as well as the working conditions and wages of workers (Deery et al., 1999). Finally, SDP show that the organization listens, considers and supports its employees, in other words, that it promotes organizational trust (Newman et al., 2018). Moreover, like OJP, no study has shown any deleterious effect of SDP on the psychological health of employees. For this reason, Guest (2017) included collective representation in his descriptive model. De Prins et al. (2018) added that the industrial relations climate is an essential factor in protecting the health of employees. Examples of SDP include formal and regular collective bargaining and consultation with employees whenever an organizational change affecting them occurs (Guest, 2017; De Prins et al., 2018).

In sum, the new integrative psychological construct of VOP has eight dimensions: PPDM, work-life balance, health and safety, recognition, career management, communication, organizational justice, and social dialogue.

\section{The Assessment of Virtuous Organizational Practices}

Significant divergences exist among researchers about how to measure organizational practices. The first concerns the source of the data. Initial studies focused on organizational practices from the perspective of $\mathrm{HR}$ actors and managers, ignoring how they were experienced by workers (Liao et al., 2009). More recently, differences in the perception of organizational practices in different professional fields (Wang et al., 2020; Beijer et al., 2021; Van Beurden et al., 2021) and the recognition that employees' attitudes and behaviors are largely determined by their perception of these practices (Edgar and Geare, 2005) have led to a growing body of research based on employee reports. For example, Beijer et al. (2021) observed that only $9 \%$ of studies published between 2000 and 2002 used an employee-level rating vs. $91 \%$ using a management-level rating, compared to $37 \%$ and 
$63 \%$, respectively, between 2015 and 2017. Following this trend, the VOPi measures the subjective VOP at the employee level.

A second difference concerns objective vs. subjective measures of organizational practices (Mendelson et al., 2011). In their literature reviews, Beijer et al. (2021) and Wang et al. (2020) found that the main difference in the scales evaluating organizational practices lay in whether they used objective (e.g., existence, frequency of use) or subjective (e.g., satisfaction) measure. According to Spector et al. (2019), these two forms of evaluation refer, respectively, to factual and perceptual constructs, the former involving cognitive and quantitative evaluations based on observable and verifiable elements, while the latter involve emotional and qualitative evaluations based on elements requiring a more personal interpretation. However, workers' health, attitudes and behaviors can be predicted more by the availability of practices than their use (Butts et al., 2013). Moreover, Beijer et al. (2021) observed that objective evaluation involves practices measured by managers, while subjective evaluation refers to practices measured by employees. In line with these studies, VOPi was developed as a subjective measure of VOP as perceived by employees.

A final difference concerns the relations between different organizational practices, their combined effect on the attitudes, behaviors and health status of employees, and consequently the statistical approach adopted in their operational modeling. Initially, the effects of these practices were considered as independent, but there is now broad agreement that they have a synergistic effect (Delery, 1998; Chadwick, 2010; Boon et al., 2019). In other words, the effects of organizational practices are mutually reinforcing, their combined effects being greater than the sum of their independent effects (Chadwick, 2010). Consequently, we hypothesize that VOP could be modeled by a global factor.

\section{VALIDATION STUDIES}

\section{Study 1: Initial Development of Virtuous Organizational Practices Inventory}

The aim of study 1 was to generate a preliminary pool of items. The deductive approach was used to develop an initial version of VOPi based on relevant theoretical and conceptual knowledge (Boateng et al., 2018), following an in-depth review of the literature and tools of the eight sub-dimensions of the VOPi.

For a short and easy-to-use tool, five items were generated per dimension, except for OJP for which eight items were created due to its multidimensional nature (Colquitt, 2001). Moreover, as previously noted, while HSP are considered as a single dimension in the APA model, many researchers consider that these two constructs are independent (Mearns et al., 2010; Zweber et al., 2016; Parker et al., 2017), and we therefore created five items for each. In total, the scale comprised 48 items; twenty were directly derived from existing scales (41.67\%; e.g., "Mon organization favorise la mobilité interne" [My organization promotes internal mobility]) and 28 were created by a committee of experts (i.e., The committee of experts included a full professor, a lecturer, a Ph.D. student and a psychologist, all specialized in work and organizational psychology; 58.33\%; e.g., "Dans mon organization, les salarié(e)s participent aux prises de décisions liées aux changements en interne" [In my organization, employees are involved in making decisions about internal changes]). The items were then randomized to avoid a contamination effect of the responses (El Akremi et al., 2018).

To check the clarity of the items, we performed two pretests. The first was carried out with 13 workers from various professional sectors, and the second with 22 experts in work psychology. Participants were asked to rate the degree of clarity of each item on a 7-point Likert scale ranging from 1 ("The item is not at all clear") to 7 ("The item is very clear"). They were asked to indicate items that were unclear by adding comments. This allowed us to identify alternative wording for items that had the lowest levels of clarity. Following their comments, we slightly reworded 11 items.

\section{Study 2: Exploratory Factor Analysis}

The aim of study 2 was to explore the factorial structure and psychometric qualities of the VOPi.

\section{Method}

The Tours-Poitiers Ethics Committee for Research, which is part of the University of Tours (France), approved this research (CERTP $n^{\circ}$ 2019-03-02). Participants were informed of the voluntary, anonymous and confidential nature of the study and were asked to give their informed consent. This study was thus conducted in accordance with the Helsinki Declaration (World Medical Association, 2013).

\section{Participants}

A total of 606 French workers (168 men, 437 women, and 1 nonrespondent) from various sectors of activity participated in this study; 256 worked in private organizations (42.24\%), 234 in nonprofit organizations (38.61\%), and 116 in public organizations $(19.14 \%)$. Their average age was 36.78 years $(S D=10.86$, range 18 to 69$)$, their average job tenure was 6.36 years $(S D=7.19)$ and their average organizational tenure was 7.96 years $(S D=8.16)$. Among the participants, 503 worked full-time (83.00\%), 102 part-time (16.83\%) and 1 did not provide this information; 522 participants were in permanent work $(86.14 \%)$; and 84 in temporary work $(13.86 \%)$.

\section{Measure}

Participants were instructed to complete the preliminary 48item version of the VOPi as follows: "The following items are about the practices of your organization. Indicate your degree of agreement with each one." They responded on a five-point Likert scale ranging from 1 ("Strongly disagree") to 5 ("Strongly agree").

\section{Statistical Analysis and Results}

In accordance with the recommendations of Tabachnick and Fidell (2013), we carried out preliminary analyses, which revealed no univariate outliers (i.e., $|z|>3.29, p<0.001$ ). The kurtosis and skewness coefficients were all acceptable, with values less than 10 for all components (George and Mallery, 2010; Kline, 2016). The mean score for all items was 3.10 out of 5 (Minimum $=2.20$; Maximum = 3.78). 
We then carried out an Exploratory Factor Analysis (EFA) using SPSS version 25. To determine the number of factors to retain, we used the most frequently used criteria, namely the Kaiser-Guttman criterion (Kaiser, 1960), the scree plot (Cattell, 1966), the proportion of variance explained (Boateng et al., 2018), and theoretical interpretability (Conway and Huffcutt, 2003). In addition, because significant and positive relationships have been found between some VOP (Simard et al., 2005; Edgar and Geare, 2009; Ogbonnaya et al., 2017; Loh et al., 2018), we used oblique rotation (Tabachnick and Fidell, 2013). In this way, we identified an eight-factor solution whose eigenvalues were all greater than 1 and explained $61.90 \%$ of the total variance of the 48 items. Items that showed cross-loading were then removed (Boateng et al., 2018). Moreover, to make VOPi as parsimonious as possible, and because researchers are increasingly creating short scales with an average of three items per dimension (Moneta, 2017; Haar et al., 2019; Décieux et al., 2020), we retained only the three items with the highest loadings per dimension. We made sure that these were representative of the measured constructs and verified the absence of redundancy in the formulation of the retained items.

A second EFA was then carried out, again using oblique rotation. A four-factor solution explaining $58.45 \%$ of the total variance of the 24 items was identified. However, this was not theoretically interpretable. We therefore performed a final EFA, fixing the theoretically expected number of factors (i.e., eight). Using the criteria described above, we retained a final eightfactor solution explaining $72.45 \%$ of the total variance with 24 items. In accordance with the recommendations of Tabachnick and Fidell (2013) and Boateng et al. (2018), no item had saturations less than 0.32 (Table 1). The internal consistency of each factor was satisfactory (Nunnally, 1978) with values ranging from 0.72 to 0.84 (Table 1). These eight factors also represented a factorial solution that was easily interpretable. An examination of the interpretability of the factors showed that the first factor corresponded to the PPDM dimension, the second to WLBP, the third to HSP, the fourth to RP, the fifth to PCM, the sixth to CP, the seventh to OJP, and the eighth to SDP (VOPi can be provided by the first author on request). Descriptive statistics of the 24 items are presented in Table 1.

Inter-item correlations are presented in Table 2 and interfactor correlations in Table 3.

\section{Study 3: Confirmatory Factor Analysis}

The purpose of Study 3 was to assess the factorial structure of the 24-item version of the VOPi identified in Study 2, through confirmatory factor analysis with a new sample. We compared alternative models to identify the best representation of the data (i.e., second-order factor model, single first-order factor, and eight first-order factors).

\section{Method}

The third study was also conducted in accordance with the Helsinki Declaration (World Medical Association, 2013), guaranteeing the anonymity, informed consent and absolute confidentiality of participants. This study was also approved by the Tours-Poitiers Ethics Committee for Research (CER-TP, $n^{\circ}$ 2019-03-02).

\section{Participants}

The sample consisted of 483 French workers, including 136 men $(28.16 \%)$, and 347 women (71.84\%). They had an average age of 39.10 years $(S D=11.58$, range 18 to 67$)$. Their average job tenure was 5.25 years $(S D=6.29)$ and their average organizational tenure was 8.00 years $(S D=8.74) ; 398$ worked full-time $(82.40 \%)$ and 85 part-time (17.60\%), and 382 participants were in permanent work $(79.09 \%)$ and 101 in temporary work $(20.91 \%)$. Finally, 232 worked in private organizations (48.03\%), 130 in public organizations (26.92\%), 119 in non-profit organizations $(24.64 \%)$, and 2 did not provide this information.

\section{Measure}

Participants completed the 24-item version of the VOPi, with the same instruction: "The following items are about the practices of your organization. Indicate your degree of agreement with each one." They responded using a five-point Likert scale ranging from 1 ("Strongly disagree") to 5 ("Strongly agree").

\section{Statistical Analysis and Results}

No univariate outliers were identified (i.e., $|z|>3.29, p<0.001$; Tabachnick and Fidell, 2013). However, and in accordance with Tabachnick and Fidell's recommendations (2013), six multivariate outliers [i.e., Mahalanobis distance greater than $\left.\chi^{2}(8)=26.12, p<0.001\right]$ were excluded, leaving 477 participants for analyses. The kurtosis and skewness coefficients were all adequate with values less than 10 for all components (George and Mallery, 2010; Kline, 2016). All components were therefore considered to be normally distributed. The average score for all items was 3.10 out of 5 (Minimum = 2.37; Maximum = 3.62). Descriptive statistics for each dimension are presented in Table 4 and correlations between dimensions in Table 5 .

Next, we performed a confirmatory factor analysis with maximum likelihood estimation method using AMOS software Version 25. We used the following fit indices: chi-square (Jöreskog, 1967), standardized root mean square residual (SRMR; Jöreskog and Sörbom, 2001; $\leq 0.05$ good fit and $\leq 0.10$ acceptable fit), root mean square error of approximation (RMSEA; Browne and Cudeck, 1989; $\leq 0.05$ good fit and $\leq 0.08$ acceptable fit), comparative fit index (CFI; Bentler, 1990; $\geq 0.90$ acceptable fit), Akaike information criterion (AIC; Akaike, 1987), and $\chi^{2} / \mathrm{df}$ (Kline, 2016).

We tested a series of models. The first was a secondorder factor model with eight first-order factors. The results demonstrated a good fit of the theoretical model to the data $\left[\chi^{2}=584.76\right.$ (244), $p<0.001 ;$ SRMR $=0.04$; RMSEA $=0.05$; $\left.\mathrm{CFI}=0.95 ; \mathrm{AIC}=744.76 ; \chi^{2} / \mathrm{df}=2.40\right]$ (Figure 1). The second model included only a single first-order factor; the fit of the theoretical model to the data was not satisfactory $\left[\chi^{2}=1255.54\right.$ (252), $p<0.001$; SRMR $=0.06$; RMSEA $=0.09$; CFI $=0.84$; $\left.\mathrm{AIC}=1399.5 ; \chi^{2} / \mathrm{df}=4.98\right]$. Finally, the third model included eight first-order factors; results indicated a good fit of the model to the data $\left[\chi^{2}=469.52(224), p<0.001 ;\right.$ SRMR $=0.03$; RMSEA $=0.05 ;$ CFI $=0.96 ;$ AIC $\left.=669.52 ; \chi^{2} / \mathrm{df}=2.10\right]$. 
TABLE 1 | Means, standard deviations, and factor loadings of the exploratory factor analysis (Study 2).

\begin{tabular}{|c|c|c|c|c|c|c|c|c|c|c|c|c|}
\hline Items & $M$ & SD & Skewness & Kurtosis & PPDM & WLBP & HSP & $\mathbf{R P}$ & PCM & $\mathrm{CP}$ & OJP & SDP \\
\hline Item 1 & 2.39 & 1.12 & 0.50 & -0.60 & 0.82 & 0.01 & 0.01 & 0.02 & 0.01 & 0.04 & 0.07 & 0.01 \\
\hline Item 2 & 2.40 & 1.07 & 0.40 & -0.61 & 0.81 & 0.02 & 0.04 & 0.00 & 0.04 & 0.05 & 0.02 & 0.02 \\
\hline Item 3 & 2.57 & 1.07 & 0.12 & -0.85 & 0.54 & 0.03 & 0.03 & 0.08 & 0.04 & 0.10 & 0.01 & 0.13 \\
\hline Item 4 & 2.88 & 1.23 & -0.05 & -1.07 & 0.06 & 0.86 & 0.07 & 0.02 & 0.10 & 0.09 & 0.02 & 0.06 \\
\hline Item 5 & 2.20 & 1.27 & 0.72 & -0.65 & 0.03 & 0.56 & 0.08 & 0.04 & 0.07 & 0.08 & 0.09 & 0.05 \\
\hline Item 6 & 3.20 & 1.23 & -0.44 & -0.89 & 0.04 & 0.52 & 0.03 & 0.17 & 0.07 & 0.04 & 0.08 & 0.06 \\
\hline Item 7 & 3.32 & 1.01 & -0.56 & 0.08 & 0.02 & 0.03 & 0.49 & 0.01 & 0.18 & 0.06 & 0.11 & 0.14 \\
\hline Item 8 & 3.03 & 1.08 & -0.24 & -0.73 & 0.06 & 0.06 & 0.72 & 0.04 & 0.05 & 0.08 & 0.02 & 0.04 \\
\hline Item 9 & 3.17 & 1.03 & -0.34 & -0.49 & 0.08 & 0.06 & 0.75 & 0.04 & 0.00 & 0.05 & 0.03 & 0.00 \\
\hline Item 10 & 3.25 & 1.15 & -0.38 & -0.71 & 0.19 & 0.02 & 0.12 & 0.52 & 0.03 & 0.16 & 0.18 & 0.02 \\
\hline Item 11 & 3.25 & 1.06 & -0.44 & -0.56 & 0.04 & 0.07 & 0.05 & 0.41 & 0.06 & 0.18 & 0.28 & 0.06 \\
\hline Item 12 & 2.98 & 1.08 & -0.26 & -0.75 & 0.04 & 0.10 & 0.03 & 0.52 & 0.13 & 0.04 & 0.05 & 0.13 \\
\hline Item 13 & 3.45 & 1.13 & -0.52 & -0.50 & 0.08 & 0.05 & 0.16 & 0.20 & 0.37 & 0.05 & 0.09 & 0.05 \\
\hline Item 14 & 3.27 & 1.06 & -0.46 & -0.46 & 0.07 & 0.02 & 0.05 & 0.24 & 0.49 & 0.18 & 0.07 & 0.00 \\
\hline Item 15 & 3.35 & 1,00 & -0.42 & -0.24 & 0.02 & 0.13 & 0.02 & 0.05 & 0.44 & 0.08 & 0.04 & 0.09 \\
\hline Item 16 & 3.43 & 1.04 & -0.79 & -0.01 & 0.08 & 0.06 & 0.07 & 0.06 & 0.01 & 0.58 & 0.08 & 0.03 \\
\hline Item 17 & 3.48 & 1.01 & -0.86 & 0.17 & 0.08 & 0.03 & 0.08 & 0.12 & 0.18 & 0.58 & 0.12 & 0.04 \\
\hline Item 18 & 3.33 & 1.08 & -0.61 & -0.34 & 0.15 & 0.12 & 0.11 & 0.13 & 0.18 & 0.33 & 0.06 & 0.09 \\
\hline Item 19 & 2.95 & 1.22 & -0.04 & -1.11 & 0.18 & 0.07 & 0.08 & 0.02 & 0.03 & 0.01 & 0.65 & 0.02 \\
\hline Item 20 & 3.18 & 0.98 & -0.37 & -0.27 & 0.11 & 0.02 & 0.09 & 0.03 & 0.06 & 0.01 & 0.59 & 0.05 \\
\hline Item 21 & 3.78 & 1.14 & -0.93 & 0.15 & 0.07 & 0.01 & 0.05 & 0.06 & 0.00 & 0.11 & 0.48 & 0.05 \\
\hline Item 22 & 3.17 & 0.91 & -0.40 & 0.19 & 0.06 & 0.02 & 0.08 & 0.02 & 0.06 & 0.07 & 0.03 & 0.80 \\
\hline Item 23 & 3.28 & 0.97 & -0.65 & 0.06 & 0.02 & 0.02 & 0.27 & 0.01 & 0.06 & 0.09 & 0.01 & 0.55 \\
\hline Item 24 & 3.09 & 0.94 & -0.43 & -0.05 & 0.01 & 0.03 & 0.13 & 0.02 & 0.09 & 0.11 & 0.06 & 0.60 \\
\hline$\alpha$ & & & & & 0.84 & 0.72 & 0.82 & 0.81 & 0.74 & 0.78 & 0.74 & 0.81 \\
\hline
\end{tabular}

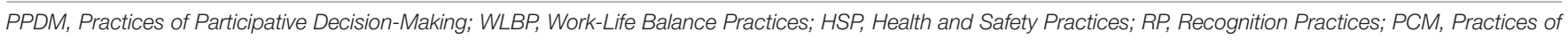

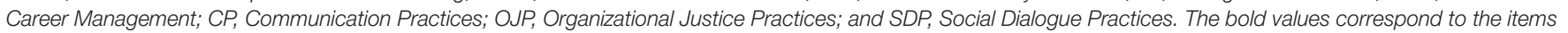
saturations selected for each dimension.

Comparison of the second-order factor model with eight firstorder factors on the one hand and the eight first-order factor model on the other revealed that the latter fit the data better than the former $\left[\Delta \chi^{2}(20)=115.24, p<0.001\right]$. However, as mentioned above, organizational practices have been shown to have a synergistic, mutually reinforcing effect, and their combination has more influence on the health, attitudes and behaviors of workers than the simple sum of their independent effects (Boon et al., 2019). For this reason, we retained the second-order model.

\section{Study 4: Virtuous Organizational Practices Inventory Convergent, Predictive and Incremental Validities}

The aim of study 4 was to examine the convergent, predictive and incremental validities of the VOPi with a new sample. PSC was used to test the convergent validity (i.e., additional predictive validity over other constructs) of the new scale because it is conceptually similar to the VOP, defined as "policies, practices and procedures for the protection of worker psychological health and safety" (Dollard and Bakker, 2010, p. 579). We then investigated the predictive validity of VOPi through job satisfaction and affective commitment. Job satisfaction refers to "a pleasurable or positive emotional state resulting from the appraisal of one's job or job experiences" (Locke, 1976, p. 1304), and affective commitment is defined as "employee's emotional attachment to, identification with, and involvement in the organization" (Meyer and Allen, 1991, p. 67). Several meta-analyses have observed positive relationships between some organizational practices (e.g., internal promotion, training, rewards, participation, work-life policies, and organizational justice) and job satisfaction on the one hand and affective commitment on the other (e.g., Meyer et al., 2002; Kooij et al., 2010; Butts et al., 2013; Colquitt et al., 2013). The final aim was to investigate the incremental validity of the VOPi on job satisfaction and affective commitment beyond the PSC.

\section{Method}

As for Studies 2 and 3, this last study was also approved by ToursPoitiers Ethics Committee for Research (CER-TP, n² 2019-03-02) and respected the Helsinki Declaration on research involving human subjects (World Medical Association, 2013).

\section{Participants}

The sample comprised 283 participants, with 105 (37.10\%) men and 178 women (62.90\%). Ages ranged from 18 to 67 years, with an average of 33.75 years $(S D=10.69)$, average job tenure of 6.31 years $(S D=8.39)$ and average organizational tenure of 7.34 years $(S D=10.41)$; 238 participants worked full-time $(84.10 \%)$ and 45 part-time $(15.90 \%), 216$ participants were in permanent work (76.33\%), and 67 in temporary work $(23.67 \%)$; 


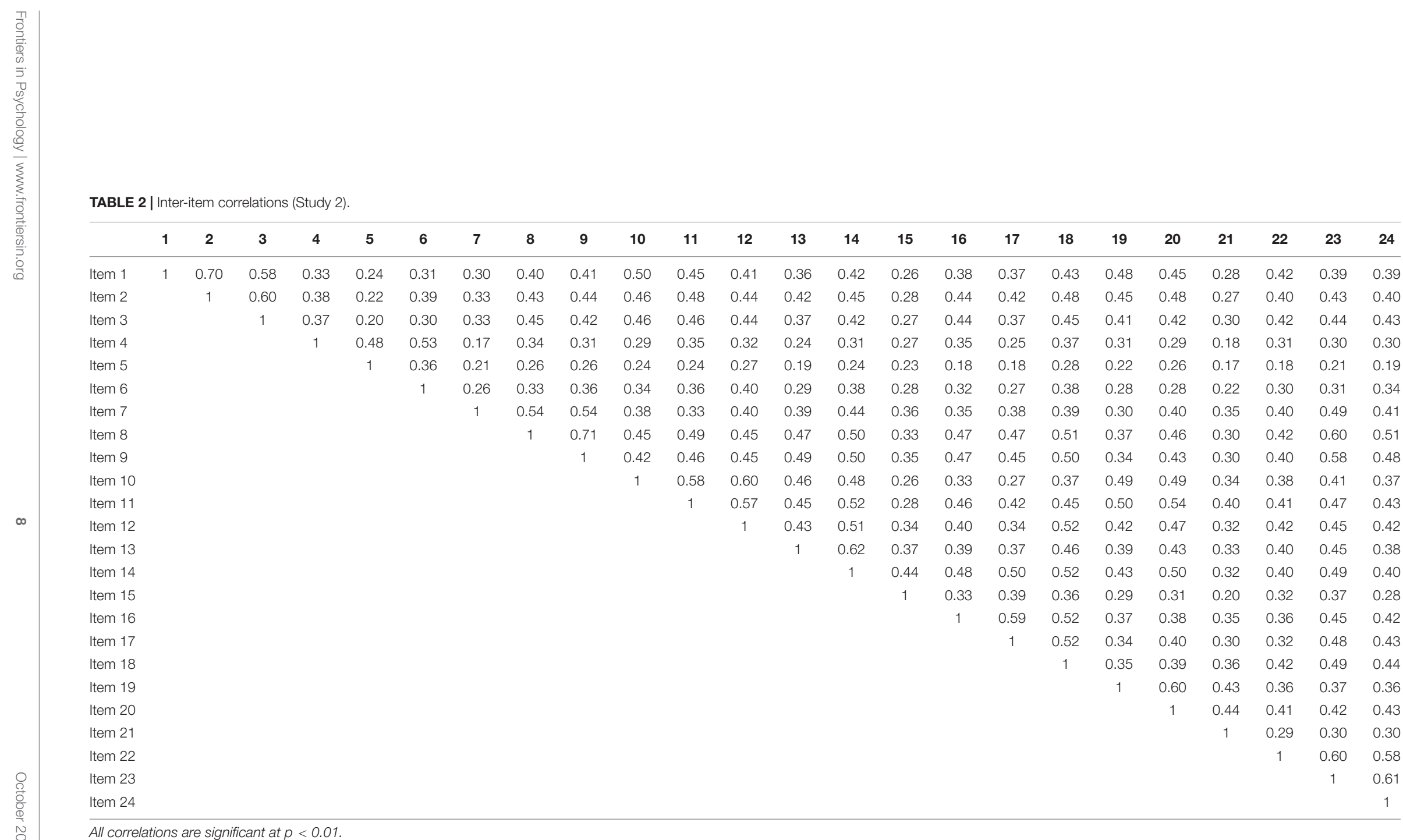


TABLE 3 | Inter-factor correlations (Study 2).

\begin{tabular}{|c|c|c|c|c|c|c|c|c|c|}
\hline & & 1 & 2 & 3 & 4 & 5 & 6 & 7 & 8 \\
\hline 1 & PPDM & 1 & 0.44 & 0.52 & 0.62 & 0.52 & 0.58 & 0.56 & 0.56 \\
\hline 2 & WLBP & & 1 & 0.41 & 0.46 & 0.40 & 0.43 & 0.38 & 0.39 \\
\hline 3 & HSP & & & 1 & 0.60 & 0.61 & 0.63 & 0.54 & 0.56 \\
\hline 4 & $\mathrm{RP}$ & & & & 1 & 0.59 & 0.56 & 0.63 & 0.57 \\
\hline 5 & PCM & & & & & 1 & 0.62 & 0.51 & 0.65 \\
\hline 6 & $\mathrm{CP}$ & & & & & & 1 & 0.53 & 0.60 \\
\hline 7 & OJP & & & & & & & 1 & 0.51 \\
\hline 8 & SDP & & & & & & & & 1 \\
\hline
\end{tabular}

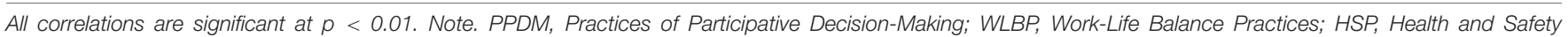

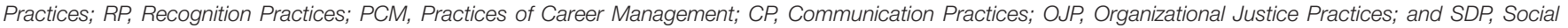
Dialogue Practices.

TABLE 4 | Descriptive statistics of the eight subdimensions of VOPi (Study 3).

\begin{tabular}{|c|c|c|c|c|c|c|c|c|}
\hline & & Min & Max & $\mathbf{M}$ & SD & Skewness & Kurtosis & $\alpha$ \\
\hline 1 & PPDM & 1 & 5 & 2.52 & 0.96 & 0.28 & -0.40 & 0.84 \\
\hline 2 & WLBP & 1 & 5 & 2.86 & 1.04 & -0.03 & -0.74 & 0.73 \\
\hline 3 & HSP & 1 & 5 & 3.19 & 0.99 & -0.40 & -0.42 & 0.83 \\
\hline 4 & $\mathrm{RP}$ & 1 & 5 & 3.11 & 1,00 & -0.17 & -0.67 & 0.85 \\
\hline 5 & PCM & 1 & 5 & 3.31 & 0.89 & -0.51 & -0.13 & 0.76 \\
\hline 6 & $\mathrm{CP}$ & 1 & 5 & 3.29 & 0.90 & -0.46 & -0.06 & 0.77 \\
\hline 7 & OJP & 1 & 5 & 3.17 & 0.94 & -0.31 & -0.45 & 0.74 \\
\hline 8 & SDP & 1 & 5 & 3.02 & 0.87 & -0.26 & -0.05 & 0.82 \\
\hline
\end{tabular}

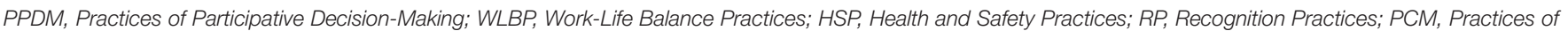
Career Management; CP, Communication Practices; OJP, Organizational Justice Practices; and SDP, Social Dialogue Practices.

TABLE 5 | Correlations between dimensions of VOPi (Study 3).

\begin{tabular}{|c|c|c|c|c|c|c|c|c|c|}
\hline & & 1 & 2 & 3 & 4 & 5 & 6 & 7 & 8 \\
\hline 1 & PPDM & 1 & 0.45 & 0.55 & 0.69 & 0.54 & 0.61 & 0.57 & 0.70 \\
\hline 2 & WLBP & & 1 & 0.47 & 0.56 & 0.48 & 0.43 & 0.35 & 0.49 \\
\hline 3 & HSP & & & 1 & 0.64 & 0.65 & 0.61 & 0.50 & 0.67 \\
\hline 4 & $\mathrm{RP}$ & & & & 1 & 0.61 & 0.64 & 0.70 & 0.69 \\
\hline 5 & PCM & & & & & 1 & 0.58 & 0.53 & 0.58 \\
\hline 6 & $\mathrm{CP}$ & & & & & & 1 & 0.62 & 0.60 \\
\hline 7 & OJP & & & & & & & 1 & 0.57 \\
\hline 8 & SDP & & & & & & & & 1 \\
\hline
\end{tabular}

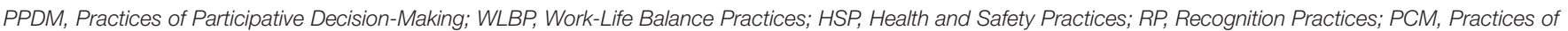
Career Management; CP, Communication Practices; OJP, Organizational Justice Practices; and SDP, Social Dialogue Practices.

185 worked in the private sector $(65.37 \%), 84$ in the public sector (29.68\%), and 14 in the non-profit sector (4.95\%).

\section{Measure}

Participants completed the four scales (i.e., VOPi, PSC, job satisfaction, and affective commitment) using a five-point Likert scale ranging from 1 ("Strongly disagree") to 5 ("Strongly agree").

Virtuous organizational practices were assessed with the 24item version of the VOPi. Analyses revealed good internal consistency for the total inventory $(\alpha=0.94)$.

Psychosocial safety climate was measured with Hall et al.'s (2010) composed of 12 items and four sub-dimensions: 3 items for management commitment (e.g., "Senior management show support for stress prevention through involvement and commitment"), 3 items for management priority (e.g., "Senior management considers employee psychological health to be as important as productivity"), 3 items for organizational communication (e.g., "There is good communication here about psychological safety issues which affect me") and 3 items for organizational participation (e.g., "Participation and consultation in psychological health and safety occurs with employees', unions' and health and safety representatives in my workplace"). The alpha for the global scale was 0.95 .

Affective commitment was measured with Meyer et al.'s (1993) composed of 6 items (e.g., "This organization has a great deal of 


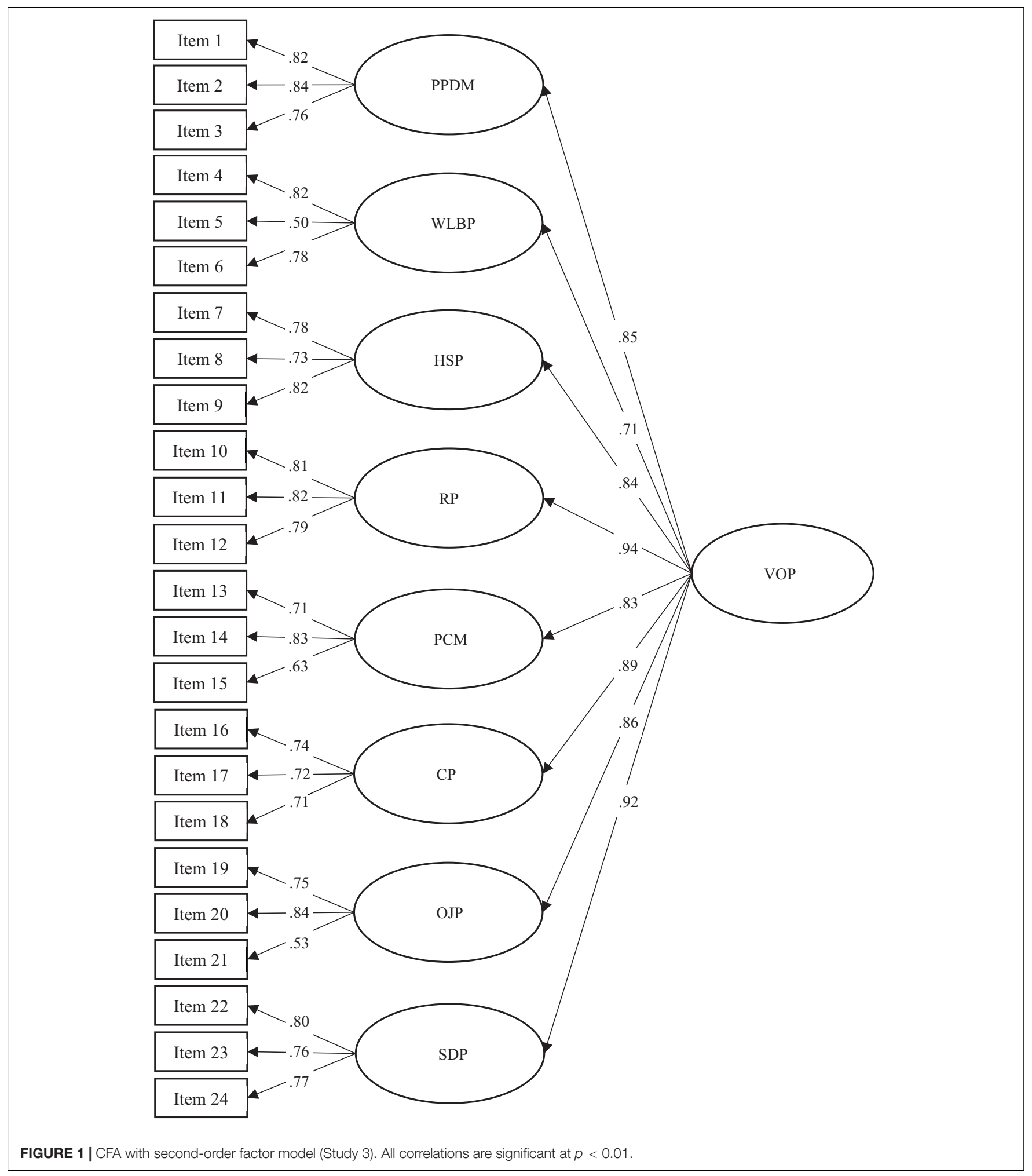

personal meaning for me"). The internal consistency of this scale was acceptable $(\alpha=0.77)$.

Job satisfaction was measured using the single item of Tavani et al. (2014; i.e., "Overall, I am satisfied with my work").

\section{Statistical Analysis and Results}

To examine convergent and predictive validity, we performed bivariate Pearson correlations between VOPi, PSC, affective commitment, and job satisfaction (Table 6). 
TABLE 6 | Convergent and predictive validity (Study 4).

\begin{tabular}{lcccc}
\hline & $\mathbf{1}$ & $\mathbf{2}$ & $\mathbf{3}$ & $\mathbf{4}$ \\
\hline 1. VOPi & 1 & 0.78 & 0.53 & 0.60 \\
2. PSC & 1 & 0.54 & 0.57 \\
3. AC & & 1 & & 0.54 \\
4. JS & & & & 1
\end{tabular}

All correlations are significant at $p<0.001$. Note. VOPi, Virtuous Organizational Practices inventory; PSC, Psychosocial Safety Climate; AC, Affective Commitment; and JS, Job Satisfaction.

The results for convergent validity demonstrated significantly positive correlations between VOP and PSC $(r=0.78, p<0.001)$. The results for predictive validity indicated significant and positive correlations between VOP on the one hand and affective commitment $(r=0.53, p<0.001)$ and job satisfaction $(r=0.60$, $p<0.001)$ on the other.

Finally, because the VOPi showed a strong, significant, and positive correlation with PSC $(r=0.78, p<0.001)$, we tested its incremental validity to predict job satisfaction and affective commitment using hierarchical regression analyses. The control variables of gender, age and education level were introduced in step 1. PSC was then introduced in step 2. Finally, VOPi was introduced in step 3. Analyses revealed that the variance inflation factors (VIF) were all less than 10, demonstrating the absence of significant multi-collinearities (Kline, 2016). Results showed that the VOPi added specific variance beyond PSC to explain job satisfaction on the one hand (adjusted $\Delta R^{2}=0.047$, $p<0.001$; Table 7) and affective commitment on the other (adjusted $\Delta R^{2}=0.019, p<0.01$; Table 8). The incremental validity of the VOPi beyond the PSC is thus clearly demonstrated for job satisfaction and affective commitment.

\section{GENERAL DISCUSSION}

As underlined at the beginning of this paper, studies of organizational practices that promote workers' psychological health have received less attention than those that are thought to contribute directly to increasing employees' performance. Moreover, these studies have only examined isolated effects and have not used an integrative conceptual framework. To fill this gap in the scientific literature and develop a more accurate measure, we therefore took an innovative conceptual approach to develop and validate a new scale of organizational practices that foster the psychological health of employees.

More precisely, this paper presents a new multifaceted construct of VOP, based on the conceptual framework of organizational virtuousness (Meyer, 2018). As these organizational practices have been widely demonstrated to promote well-being (Kooij et al., 2010; Butts et al., 2013; Colquitt et al., 2013), they can be defined as "virtuous," that is to say contributing to the optimal psychological functioning of workers (Bright et al., 2006). Based on the APA's descriptive model of a Psychologically Healthy Workplace, coupled with a review of the literature on practices related to workers' psychological health, we identified eight VOP: (1) participation in decision-making,
(2) work-life balance, (3) health and safety, (4) recognition, (5) career management, (6) communication, (7) organizational justice, and (8) social dialogue. The first six practices were directly derived from the APA model and the last two from the literature review. The VOP is thus a well-defined integrative construct of formal organizational practices that focus on employees' psychological well-being and optimal health.

The second aim of the present research was to validate a new scale to assess these perceived VOP. Four studies were conducted to develop and test the VOPi in samples of French workers. The goal of Study 1 was to create a pool of 48 items reflecting the eight sub-dimensions of VOP. In study 2, EFA identified a 24-item solution corresponding to the theoretically relevant sub-dimensions of VOP, explaining $72.45 \%$ of the total variance. While some authors recommend studying HSP as two independent constructs (Mearns et al., 2010; Zweber et al., 2016; Parker et al., 2017), in the present study, the items assessing these practices loaded on the same factor, validating the "health and safety" dimension in the APA model. Study 3 confirmed the satisfactory psychometric qualities of the VOPi with a secondorder factor model. More precisely, analysis revealed that the eight first-order factor model fit the data better than the secondorder factor model. However, the latter was consistent with the concept of synergy frequently mentioned in the research field of organizational practices (Chadwick, 2010; Boon et al., 2019). Indeed, the scientific literature shows that the effectiveness of one practice in an organization depends on other practices (Delery, 1998), and that when they are coherent, they have synergistic effects (Chadwick, 2010; Boon et al., 2019). In other words, their combined effects have a greater weight on the attitudes and behaviors of professionals than the sum of their independent effects. Due to this synergistic effect, organizational practices are regularly referred to as a "system" (e.g., High Performance Work System; High Involvement Work System). As observed by Boon et al. (2019) in their recent literature review: "Over the past three decades, a shared consensus has developed that the focus should be on HR systems rather than individual HR practices because the effects of HR practices are likely to depend on the other practices within the system" (p. 2498). We therefore retained the second-order model, as it illustrates the complex links between different organizational practices. Finally, Study 4 confirmed the convergent validity (i.e., with psychological safety climate), the predictive validity (i.e., job satisfaction, affective commitment) and incremental validity of the VOPi in relation to the PSC to predict workers' job satisfaction and affective commitment. The predictive and incremental validity of the VOPi demonstrates that our integrative construct provides a better understanding of the combined effects of different VOP on employees' wellbeing at work. Moreover, the scrupulous respect of the procedure for creating and validating this tool overcomes the limitations observed by Robinson (2018) and Beijer et al. (2021) in their literature reviews of the development of scales in the field of human resources. The deliberately short format of the VOPi also significantly reduces its administration time, despite the number of dimensions measured, so that it can be easily combined with other tools in future research and administered several times without major difficulty. 
TABLE 7 | Incremental validity of VOPi on job satisfaction.

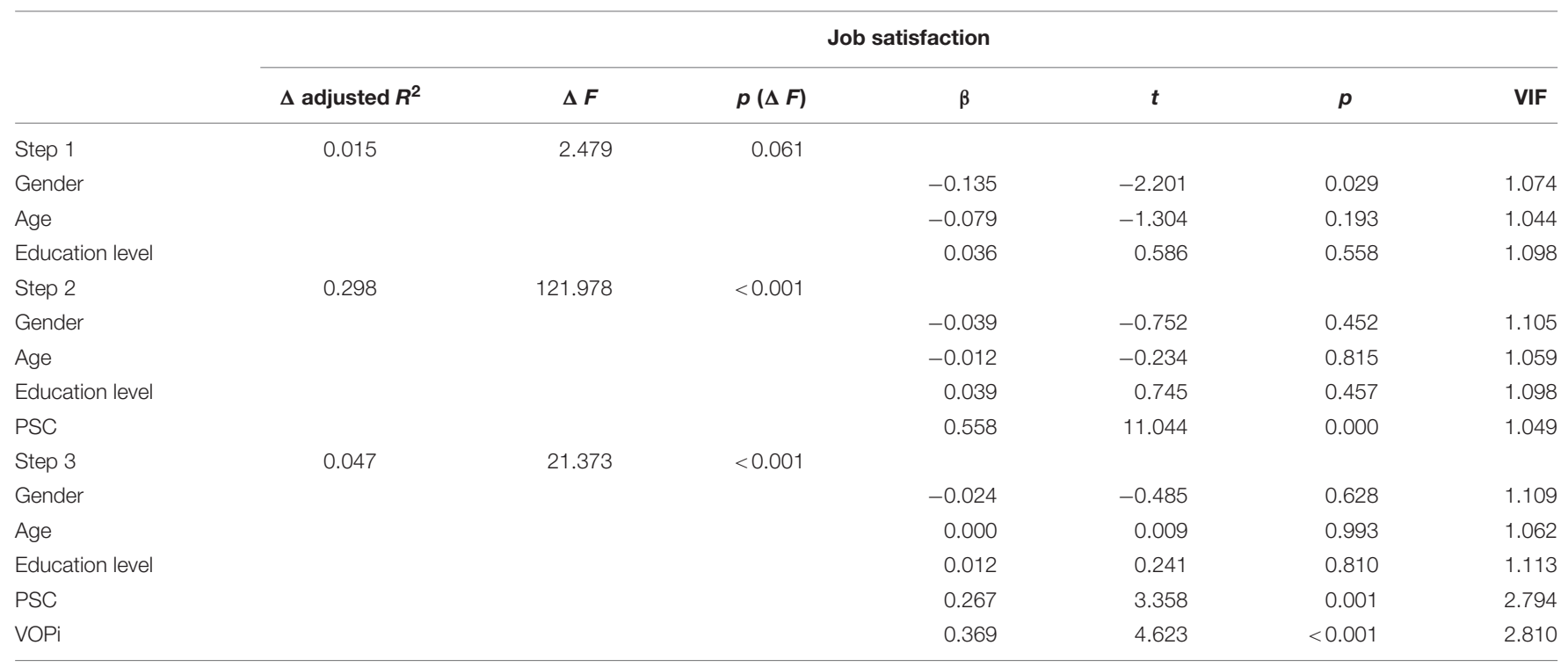

$\Delta$ adjusted $R^{2}$, variation of adjusted $R$ Square; $\Delta F$, variation of $F ; p(\Delta F)$, significance of the variation of $F$; $\beta$, standardized beta coefficient; and VIF, variance inflation factor.

TABLE 8 | Incremental validity of VOPi on affective commitment.

\begin{tabular}{|c|c|c|c|c|c|c|c|}
\hline & \multicolumn{7}{|c|}{ Affective commitment } \\
\hline Gender & & & & -0.047 & -0.758 & 0.449 & 1.074 \\
\hline Age & & & & 0.010 & 0.170 & 0.865 & 1.044 \\
\hline Education level & & & & 0.045 & 0.725 & 0.469 & 1.098 \\
\hline Age & & & & 0.078 & 1.514 & 0.131 & 1.059 \\
\hline Education level & & & & 0.048 & 0.911 & 0.363 & 1.098 \\
\hline PSC & & & & 0.564 & 11.010 & 0.000 & 1.049 \\
\hline Step 3 & 0.019 & 8.762 & 0.003 & & & & \\
\hline Gender & & & & 0.059 & 1.144 & 0.253 & 1.109 \\
\hline
\end{tabular}

$\Delta$ adjusted $R^{2}$, variation of adjusted $R$ Square; $\Delta F$, variation of $F ; p(\Delta F)$, significance of the variation of $F ; \beta$, standardized beta coefficient; and VIF, variance inflation factor.

Although the development and psychometric validation of the VOPi followed a rigorous procedure using several samples of professionals, certain limitations should be mentioned. First, the samples for the second, third and fourth studies were predominantly female. Although findings are inconsistent, several studies have shown that gender moderates the influence of organizational practices on certain employee attitudes and behaviors (Qiao et al., 2009; Andersén and Andersén, 2019; Shin et al., 2020). Future research should thus test the gender invariance of VOPi (Fouquereau et al., 2018) in order to "determine if items used in survey-type instruments mean the same things to members of different groups" (Cheung and
Rensvold, 2002, p. 233). Secondly, the VOPi was validated in a French context. However, according to Rabl et al. (2014), cultural differences could influence the organizational practices used in different countries. Therefore, it would also be interesting to test the cultural invariance of our new tool (Zhou et al., 2019). The validation process could also be extended, notably by conducting a test-retest measure to verify the consistency of workers' perceptions of VOP over time (Cohen and Swerdlik, 2017) and a test of the social desirability of the scale (King and Bruner, 2000). Thirdly, it would be interesting to test the structure of the VOPi in other samples using bifactor exploratory structural equation modeling, a statistical approach increasingly used by 
the scientific community (Fadda et al., 2020; Gu et al., 2020) as it enables the variance explained by a global factor (e.g., VOP) to be examined simultaneously with the variance explained by specific factors (e.g., eight sub-dimensions), which is not possible with a hierarchical model (Morin et al., 2016). Adopting such a method based on data collection would support our innovative conceptualization and operationalization of VOP. Fourthly, we kept a second-order factor that does not allow us to understand the effects of different combinations of VOP. It would be interesting in a future study to use Latent Profile Analysis to identify various VOP profiles and their more or less favorable effects on the psychological health of employees. Finally, while the predictive validity of the VOPi on job satisfaction and organizational commitment was demonstrated, it would be interesting to test it on other indicators of wellbeing. Indeed, because VOP promote the psychological health of workers, their relations with flow at work ( $\mathrm{Gu}$ et al., 2020), flourishing (Diener et al., 2010), or optimal psychological functioning (Jaotombo, 2019) could further confirm their virtuous nature.

Although the validation process should be continued in future research, we hope that the VOPi will contribute to a better understanding of organizational practices favorable to the health of employees, and more broadly to other positive effects. In line with previous studies that have demonstrated relationships between employee well-being on the one hand and individual and organizational performance on the other (Judge et al., 2001; Ford et al., 2011), our results suggest avenues for future research from the perspective of mutual gains (Van De Voorde et al., 2012), whereby employees and employers both benefit from organizational practices that foster employee well-being, leading in turn to improved operational and financial performance. In other words, organizations that implement VOP protect workers' psychological health, which in turn contributes indirectly to the organization's effectiveness.

From an applied perspective, the construct of VOP and its associated inventory (VOPi) are also interesting and useful for consultants and managers. First, because VOP are designed the strategic level by the employer (Wright and Nishii, 2006) and are organizational determinants of the work environment (Bakker and Demerouti, 2007; Hobfoll, 2011), their implementation and optimization are related to primary prevention (i.e., prevention of disease before it occurs). However, although authors agree that primary prevention is significantly more effective than secondary and tertiary prevention in preserving the health of professionals (Rouat et al., 2017), they also observe that it is less common (Hansez et al., 2009). VOP therefore represent a new, innovative and relevant framework for interventions in the field of psychological health at work.

Secondly, the VOPi complements the set of tools used by professionals to diagnose and support work organizations. It is a short and reliable scale to assess perceived VOP and their effect on workers' psychological health and attitudes (i.e., job satisfaction, affective commitment), going beyond existing tools, such as the PSC scale (Hall et al., 2010).

Moreover, the multidimensional structure of the VOPi offers the possibility of using the whole or only some dimensions of the inventory. It also allows professionals and organizations to diagnose and compare the use of VOP. It can be used to identify: (1) the practices to be capitalized on to promote the quality of life at work of employees because the analyses show that they had the strongest positive relationships with the employees' health, attitudes and positive behaviors, and (2) the practices perceived as being under-used and requiring optimization. Use of the VOPi in an organization and identifying the organizational practices to be optimized would thus make it possible to recommend actions to be set up for each type of practice. For example, PPDM could be promoted by scheduling consultation or problemsolving groups, allowing employees to express their opinions on specific issues and thus contribute to collective decisions. WLBP could be optimized by giving employees opportunities to organize their work flexibly in order to meet the demands of their different life roles (e.g., flexible hours, part-time work, and telecommuting), or giving them tangible support (e.g., financial assistance and child-care facilities). Finally, VOPi could also be used to compare departments within the same organization, organizations in the same group, or groups in the same sector, in order to identify professional environments where VOP should be optimized as a priority.

\section{CONCLUSION}

In conclusion, we hope that the new meta-construct of VOP will contribute to the conceptual clarification of organizational practices favorable to the psychological health of employees and to stimulating research in this field by providing a new statistically valid inventory (VOPi) filling a gap in the literature and in the promotion of psychological health at work.

\section{DATA AVAILABILITY STATEMENT}

The raw data supporting the conclusions of this article will be made available by the authors, without undue reservation. VOPi can be provided by the corresponding author on request.

\section{ETHICS STATEMENT}

The studies involving human participants were reviewed and approved by the Tours-Poitiers Ethics Committee for Research (CER-TP, n_ 2019-03-02). Written informed consent for participation was required for this study in accordance with the national legislation and the institutional requirements.

\section{AUTHOR CONTRIBUTIONS}

JA-B, EF, and SC contributed to the conception and design of the study, and wrote the first draft of the manuscript. JA-B and FL carried out the data collection. HC and JA-B organized the database and performed the statistical analyses. All authors contributed to manuscript revision, read, and approved the submitted version. 


\section{REFERENCES}

Adams, J. S. (1965). "Inequity in social exchange," in Advances in experimental social psychology, ed. L. Berkowitz (New York, NY: Academic press), 267-299.

Akaike, H. (1987). Factor analysis and AIC. Psychometrika 52, 317-332. doi: 10. 1007/BF02294359

Andersén, J., and Andersén, A. (2019). Are high-performance work systems (HPWS) appreciated by everyone? The role of management position and gender on the relationship between HPWS and affective commitment. Empl. Relat. 41, 1046-1064. doi: 10.1108/ER-03-2018-0080

Armstrong-Stassen, M., and Stassen, K. (2013). Professional development, targetspecific satisfaction, and older nurse retention. Career Dev. Int. 18, 673-693. doi: 10.1108/CDI-08-2013-0102

Armstrong-Stassen, M., and Ursel, N. D. (2009). Perceived organizational support, career satisfaction, and the retention of older workers. J. Occup. Organ. Psychol. 82, 201-220. doi: 10.1348/096317908X288838

Avgoustaki, A. (2015). Work Uncertainty and Extensive Work Effort: The Mediating Role of Human Resource Practices. Ind. Labor Relat. Rev. 69, 1-27. doi: $10.1177 / 0019793915614584$

Bae, K. B., and Goodman, D. (2014). The Influence of Family-Friendly Policies on Turnover and Performance in South Korea. Public Person. Manage. 43, 520-542. doi: 10.1177/0091026014536055

Bagdadli, S., and Gianecchini, M. (2019). Organizational career management practices and objective career success: A systematic review and framework. Hum. Resour. Manag. Rev. 29, 353-370. doi: 10.1016/j.hrmr.2018. 08.001

Bakker, A. B., and Demerouti, E. (2007). The Job Demands-Resources model: State of the art. J. Manag. Psychol. 22, 309-328. doi: 10.1108/026839407107 33115

Beijer, S., Peccei, R., van Veldhoven, M., and Paauwe, J. (2021). The turn to employees in the measurement of human resource practices: A critical review and proposed way forward. Hum. Resour. Manag. J. 31, 1-17. doi: 10.1111/ 1748-8583.12229

Bentler, P. M. (1990). Comparative Fit Indexes in Structural Models. Psychol. Bull. 107, 238-246.

Boateng, G. O., Neilands, T. B., Frongillo, E. A., Melgar-Quiñonez, H. R., and Young, S. L. (2018). Best Practices for Developing and Validating Scales for Health, Social, and Behavioral Research: A Primer. Public Health Front. 6:149. doi: 10.3389/fpubh.2018.00149

Bogler, R., and Somech, A. (2005). Organizational citizenship behavior in school: How does it relate to participation in decision making? J. Educ. Adm. 43, 420-438. doi: 10.1108/09578230510615215

Boon, C., Den Hartog, D. N., and Lepak, D. P. (2019). A Systematic Review of Human Resource Management Systems and Their Measurement. J. Manage. 45, 2498-2537. doi: 10.1177/0149206318818718

Boon, C., Den Hartog, D. N., Boselie, P., and Paauwe, J. (2011). The relationship between perceptions of HR practices and employee outcomes: Examining the role of person-organisation and person-job fit. Int. J. Hum. Resource. Manag. 22, 138-162. doi: 10.1080/09585192.2011.538978

Boxall, P., and Macky, K. (2014). High-involvement work processes, work intensification and employee well-being. Work. Employ. Soc. 28, 963-984. doi: 10.1177/0950017013512714

Bright, D. S., Cameron, K. S., and Caza, A. (2006). The Amplifying and Buffering Effects of Virtuousness in Downsized Organizations. J. Bus. Ethics 64, 249-269. doi: 10.1007/s10551-005-5904-4

Browne, M. W., and Cudeck, R. (1989). Single Sample Cross-Validation Indices for Covariance Structures. Multivariate. Behav. Res. 24, 445-455. doi: 10.1207/ S15327906MBR2404_4

Brun, J.-P., and Dugas, N. (2005). La reconnaissance au travail: Analyse d'un concept riche de sens. Gestion 30, 79-88. doi: 10.3917/riges.302.0079

Butts, M. M., Casper, W. J., and Yang, T. S. (2013). How important are work-family support policies? A meta-analytic investigation of their effects on employee outcomes. J. Appl. Psychol. 98, 1-25. doi: 10.1037/a0030389

Cameron, K. S. (2008). Paradox in Positive Organizational Change. J. Appl. Behav. Sci. 44, 7-24. doi: 10.1177/0021886308314703

Cameron, K. S., and Caza, A. (2004). Introduction: Contributions to the Discipline of Positive Organizational Scholarship. Am. Behav. Sci. 47, 731-739. doi: 10. $1177 / 0002764203260207$
Cameron, K. S., Bright, D., and Caza, A. (2004). Exploring the Relationships between Organizational Virtuousness and Performance. Am. Behav. Sci. 47, 766-790. doi: 10.1177/0002764203260209

Cameron, K. S., Quinn, R. E., and Dutton, J. E. (2003). Positive Organizational Scholarship: Foundations of a New Discipline. San Francisco, CA: BerrettKoehler. doi: 10.1007/978-3-8350-9106-1_2

Cattell, R. B. (1966). The Scree Plot Test for the Number of Factors. Multivar. Behav. Res. 1, 245-276. doi: 10.1207/s15327906mbr0102_10

Chadwick, C. (2010). Theoretic insights on the nature of performance synergies in human resource systems: Toward greater precision. Hum. Resour. Manag. Rev. 20, 85-101. doi: 10.1016/j.hrmr.2009.06.001

Cheung, G. W., and Rensvold, R. B. (2002). Evaluating Goodness-of-Fit Indexes for Testing Measurement Invariance. Struct. Equ. Modeling 9, 233-255. doi: 10.1207/S15328007SEM0902_5

Christian, M. S., Bradley, J. C., Wallace, J. C., and Burke, M. J. (2009). Workplace safety: A meta-analysis of the roles of person and situation factors. J. Appl. Psychol. 94, 1103-1127. doi: 10.1037/a0016172

Cogin, J. A., Sanders, K., and Williamson, I. O. (2017). Work-life support practices and customer satisfaction: The role of TMT composition and country culture: Work-life support practices and customer satisfaction. Hum. Resour. Manage. 57, 279-291. doi: $10.1002 / \mathrm{hrm} .21833$

Cohen, R. J., and Swerdlik, M. E. (2017). Psychological testing and assessment, 9th Edn. New York,NY: McGraw-Hill Education.

Colquitt, J. A. (2001). On the dimensionality of organizational justice: A construct validation of a measure. J. Appl. Psychol. 86, 386-400. doi: 10.1037/0021-9010. 86.3.386

Colquitt, J. A., Conlon, D. E., Wesson, M. J., Porter, C. O. L. H., and Ng, K. Y. (2001). Justice at the millennium: A meta-analytic review of 25 years of organizational justice research. J. Appl. Psychol. 86, 425-445. doi: 10.1037/00219010.86.3.425

Colquitt, J. A., Scott, B. A., Rodell, J. B., Long, D. M., Zapata, C. P., Conlon, D. E., et al. (2013). Justice at the millennium, a decade later: A meta-analytic test of social exchange and affect-based perspectives. J. Appl. Psychol. 98, 199-236. doi: $10.1037 / \mathrm{a} 0031757$

Combs, J., Liu, Y., Hall, A., and Ketchen, D. (2006). How much do HighPerformance Work Practices Matter? A Meta-Analysis of Their Effects on Organizational Performance. Pers. Psychol. 59, 501-528. doi: 10.1111/j.17446570.2006.00045.x

Conway, E., and Monks, K. (2008). HR practices and commitment to change: An employee-level analysis. Hum. Resour. Manag. J. 18, 72-89. doi: 10.1111/j.17488583.2007.00059.x

Conway, J. M., and Huffcutt, A. I. (2003). A Review and Evaluation of Exploratory Factor Analysis Practices in Organizational Research. Organ. Res. Methods 6, 147-168. doi: 10.1177/1094428103251541

Cooper, B., Wang, J., Bartram, T., and Cooke, F. L. (2019). Well-being-oriented human resource management practices and employee performance in the Chinese banking sector: The role of social climate and resilience. Hum. Resour. Manage. 58, 85-97. doi: 10.1002/hrm.21934

De Prins, P., Stuer, D., and Gielens, T. (2018). Revitalizing social dialogue in the workplace: The impact of a cooperative industrial relations climate and sustainable HR practices on reducing employee harm. Int. J. Hum. Resour. Manag. 31, 1684-1704. doi: 10.1080/09585192.2017.1423098

Décieux, J. P., Sischka, P. E., Schumacher, A., and Willems, H. (2020). Psychometrical Properties of a French Version of the General Self-Efficacy Short Scale (ASKU). Swiss J. Psychol. 79, 15-25. doi: 10.1024/1421-0185/a000233

Deery, S. J., and Iverson, R. D. (2005). Labor-Management Cooperation: Antecedents and Impact on Organizational Performance. Ind. Labor Relat. Rev. 58, 588-609. doi: 10.1177/001979390505800404

Deery, S. J., Iverson, R. D., Buttigieg, D. M., and Zatzick, C. D. (2014). Can Union Voice Make a Difference? The Effect of Union Citizenship Behavior on Employee Absence: The Effect of Union Citizenship Behavior on Employee Absence. Hum. Resour. Manage. 53, 211-228. doi: 10.1002/hrm.21549

Deery, S., Iverson, R., and Erwin, P. (1999). Industrial Relations Climate, Attendance Behaviour and the Role of Trade Unions. Br. J. Ind. Relat. 37, 533-558. doi: 10.1111/1467-8543.00141

Delery, J. E. (1998). Issues of fit in strategic human resource management: Implications for research. Hum. Resour. Manag. Rev. 8, 289-309. doi: 10.1016/ S1053-4822(98)90006-7 
Diener, E., Wirtz, D., Tov, W., Kim-Prieto, C., Choi, D., Oishi, S., et al. (2010). New Well-being Measures: Short Scales to Assess Flourishing and Positive and Negative Feelings. Soc. Indic. Res. 97, 143-156. doi: 10.1007/s11205-0099493-y

Dollard, M. F., and Bakker, A. B. (2010). Psychosocial safety climate as a precursor to conducive work environments, psychological health problems, and employee engagement. J. Occup. Organ. Psychol. 83, 579-599. doi: 10.1348/ 096317909X470690

Dollard, M. F., Opie, T., Lenthall, S., Wakerman, J., Knight, S., Dunn, S., et al. (2012). Psychosocial safety climate as an antecedent of work characteristics and psychological strain: A multilevel model. Work. Stress. 26, 385-404. doi: 10.1080/02678373.2012.734154

Domínguez-Falcón, C., Martín-Santana, J. D., and De Saá-Pérez, P. (2016). Human resources management and performance in the hotel industry: The role of the commitment and satisfaction of managers versus supervisors. Int. J. Contemp. Hosp. Manag. 28, 490-515. doi: 10.1108/EUM0000000001079

Edgar, F., and Geare, A. (2005). HRM practice and employee attitudes: Different measures - different results. Pers. Rev. 34, 534-549. doi: 10.1108/ 00483480510612503

Edgar, F., and Geare, A. (2009). Inside the "black box" and "HRM". Int. J. Manpow. 30, 220-236. doi: 10.1108/01437720910956736

El Akremi, A., Gond, J.-P., Swaen, V., De Roeck, K., and Igalens, J. (2018). How Do Employees Perceive Corporate Responsibility? Development and Validation of a Multidimensional Corporate Stakeholder Responsibility Scale. J. Manage. 44, 619-657. doi: 10.1177/0149206315569311

El Akremi, A., Sassi, N., and Bouzidi, S. (2009). Rôle de la reconnaissance dans la construction de l'identité au travail. Relat. Ind. 64, 662-684. doi: 10.7202/ 038878ar

Fadda, D., Quevedo-Aguado, M. P., Benavente Cuesta, M. H., and Scalas, L. F. (2020). The Multidimensional and Hierarchical Nature of the Questionnaire for Eudaimonic Wellbeing: A Bifactor-ESEM Representation in a Spanish Sample. Front. Psychol. 11:422. doi: 10.3389/fpsyg.2020.00422

Fall, A. (2015). Reconnaissance au travail: Validation d'une échelle de mesure dans le contexte des entreprises. Eur. Rev. Appl. Psychol. 65, 189-203. doi: 10.1016/j. erap.2015.07.001

Fallon, B. J., and Rice, S. M. (2015). Investment in staff development within an emergency services organisation: Comparing future intention of volunteers and paid employees. Int. J. Hum. Resource. Manag. 26, 485-500. doi: 10.1080/ 09585192.2011.561222

Ford, M. T., Cerasoli, C. P., Higgins, J. A., and Decesare, A. L. (2011). Relationships between psychological, physical, and behavioural health and work performance: A review and meta-analysis. Work. Stress. 25, 185-204. doi: 10.1080/02678373. 2011.609035

Fouquereau, E., Bosselut, G., Chevalier, S., Coillot, H., Demulier, V., Becker, C., et al. (2018). Better Understanding the Workers' Retirement Decision Attitudes: Development and Validation of a New Measure. Front. Psychol. 9:2429. doi: 10.3389/fpsyg.2018.02429

George, D., and Mallery, P. (2010). SPSS for Windows step by step: A simple guide and reference, 10th Edn. Boston: Allyn \& Bacon.

Godard, J. (2001). High Performance and the Transformation of Work? The Implications of Alternative Work Practices for the Experience and Outcomes of Work. Ind. Labor Relat. Rev. 54, 776-805. doi: 10.2307/2696112

Gragnano, A., Miglioretti, M., Frings-Dresen, M. H. W., and de Boer, A. G. E. M. (2017). Adjustment between work demands and health needs: Development of the Work-Health Balance Questionnaire. Rehabil. Psychol. 62, 374-386. doi: 10.1037/rep0000121

Grawitch, M. J., Trares, S., and Kohler, J. M. (2007). Healthy workplace practices and employee outcomes. Int. J. Stress Manag. 14, 275-293. doi: 10.1037/10725245.14.3.275

Greenberg, J. (1993). "The social side of fairness: Interpersonal and informational classes of organizational justice," in Justice in the workplace: Approaching fairness in human resource management, ed. R. Cropanzano (Hillsdale: Lawrence Erlbaum Associates), 79-103.

Gu, H., Zhonglin, W., and Xitao, F. (2020). Investigating the Multidimensionality of the Work-Related Flow Inventory (WOLF): A Bifactor Exploratory Structural Equation Modeling Framework. Front. Psychol. 11:740. doi: 10.3389/ fpsyg. 2020.00740
Guest, D. E. (2017). Human resource management and employee well-being: Towards a new analytic framework. Hum. Resour. Manag. J. 27, 22-38. doi: 10.1111/1748-8583.12139

Guthrie, J. P., Flood, P. C., Liu, W., and MacCurtain, S. (2009). High performance work systems in Ireland: Human resource and organizational outcomes. Int. J. Hum. Resource. Manag. 20, 112-125. doi: 10.1080/09585190802528433

Haar, J. M., Sune, A., Russo, M., and Ollier Malaterre, A. (2019). A Cross National Study on the Antecedents of Work-Life Balance from the Fit and Balance Perspective. Soc. Indic. Res. 142, 261-282. doi: 10.1007/s11205-0181875-6

Hall, G. B., Dollard, M. F., and Coward, J. (2010). Psychosocial safety climate: Development of the PSC-12. Int. J. Stress Manag. 17, 353-383. doi: 10.1037/ a0021320

Han, J., Sun, J.-M., and Wang, H.-L. (2020). Do high performance work systems generate negative effects? How and when? Hum. Resour. Manag. Rev. 30:100699. doi: 10.1016/j.hrmr.2019.100699

Hansez, I., Bertrand, F., and Barbier, M. (2009). Évaluation des pratiques de diagnostic de stress au sein d'entreprises belges: Facteurs bloquants et facteurs stimulants. Trav. Hum. 72, 127-153. doi: 10.3917/th.722.0127

Hill, E. J., Grzywacz, J. G., Allen, S., Blanchard, V. L., Matz-Costa, C., Shulkin, S., et al. (2008). Defining and conceptualizing workplace flexibility. Community. Work. Fam. 11, 149-163. doi: 10.1080/13668800802024678

Hobfoll, S. E. (2011). Conservation of resource caravans and engaged settings: Conservation of resource caravans. J. Occup. Organ. Psychol. 84, 116-122. doi: 10.1111/j.2044-8325.2010.02016.x

Huang, Y., Zohar, D., Robertson, M. M., Garabet, A., Lee, J., and Murphy, L. A. (2013). Development and validation of safety climate scales for lone workers using truck drivers as exemplar. Transp. Res. Part. F Traffic. Psychol. Behav. 17, 5-19. doi: 10.1016/j.trf.2012.08.011

Huettermann, H., and Bruch, H. (2019). Mutual Gains? Health-Related HRM, Collective Well-Being and Organizational Performance. J. Manag. Stud. 56, 1045-1072. doi: 10.1111/joms.12446

Jahn, E. W., Thompson, C. A., and Kopelman, R. E. (2003). Rationale and construct validity evidence for a measure of perceived organizational family support (POFS): Because purported practices may not reflect reality. Community. Work. Fam. 6, 123-140. doi: 10.1080/13668800302545

Jaotombo, F. F. (2019). Le fonctionnement optimal psychologique: Apports conceptuels et méthodologiques. Psychol. Trav. Organ. 25, 281-300. doi: 10. 1016/j.pto.2019.06.001

Jensen, J. M., Patel, P. C., and Messersmith, J. G. (2013). High-Performance Work Systems and Job Control: Consequences for Anxiety, Role Overload, and Turnover Intentions. J. Manage. 39, 1699-1724. doi: $10.1177 / 0149206311419663$

Jiang, K., Lepak, D. P., Hu, J., and Baer, J. C. (2012). How Does Human Resource Management Influence Organizational Outcomes? A Meta-analytic Investigation of Mediating Mechanisms. Acad. Manage. J. 55, 1264-1294. doi: 10.5465/amj.2011.0088

Jöreskog, J., and Sörbom, D. (2001). LISREL 8.50. Chicago, IL: Scientific Software. Jöreskog, K. G. (1967). Some contributions to maximum likelihood factor analysis. Psychometrika 32, 443-482. doi: 10.1007/BF02289658

Judge, T. A., Thoresen, C. J., Bono, J. E., and Patton, G. K. (2001). The job satisfaction-job performance relationship: a qualitative and quantitative review. Psychol. Bull. 127, 376-407. doi: 10.1037/0033-2909.127.3.376

Kaiser, H. F. (1960). The Application of Electronic Computers to Factor Analysis. Educ. Psychol. Meas. 20, 141-151. doi: 10.1177/001316446002000116

Kelloway, E. K., and Day, A. L. (2005). La constitution d'un milieu de travail sain: Ce que nous savons jusqu'à maintenant. Can. J. Behav. Sci. 37, 236-249. doi: $10.1037 /$ h0092529

King, M. F., and Bruner, G. C. (2000). Social desirability bias: A neglected aspect of validity testing. Psychol. Mark. 17, 79-103.

Kline, R. B. (2016). Principles and Practice of Structural Equation Modeling. New York, NY: The Guilford Press.

Kong, H., Cheung, C., and Song, H. (2011). Hotel career management in China: Developing a measurement scale. Int. J. Hosp. Manag. 30, 112-118. doi: 10.1016/ j.ijhm.2010.07.003

Kooij, D. T. A. M., Jansen, P. G. W., Dikkers, J. S. E., and De Lange, A. H. (2010). The influence of age on the associations between HR practices and both 
affective commitment and job satisfaction: A meta-analysis. J. Organ. Behav. 31, 1111-1136. doi: 10.1002/job.666

Kroon, B., van de Voorde, K., and van Veldhoven, M. (2009). Cross-level effects of high-performance work practices on burnout: Two counteracting mediating mechanisms compared. Pers. Rev. 38, 509-525. doi: 10.1108/ 00483480910978027

Lages, C., Lages, C. R., and Lages, L. F. (2005). The RELQUAL scale: A measure of relationship quality in export market ventures. J. Bus. Res. 58, 1040-1048. doi: 10.1016/j.jbusres.2004.03.001

Lavelle, J., Gunnigle, P., and McDonnell, A. (2010). Patterning employee voice in multinational companies. Hum. Relat. 63, 395-418. doi: 10.1177/ 0018726709348935

Le, H., Jiang, Z., Fujimoto, Y., and Nielsen, I. (2018). Inclusion and affective wellbeing: Roles of justice perceptions. Pers. Rev. 47, 805-820. doi: 10.1108/PR-032017-0078

Liao, H., Toya, K., Lepak, D. P., and Hong, Y. (2009). Do they see eye to eye? Management and employee perspectives of high-performance work systems and influence processes on service quality. J. Appl. Psychol. 94, 371-391. doi: 10.1037/a0013504

Locke, E. A. (1976). “The nature and causes of job satisfaction," in Handbook of industrial and organizational psychology, ed. M. D. Dunnette (Chicago, IL: Rand McNally), 1297-1351.

Loh, M. Y., Idris, M. A., Dollard, M. F., and Isahak, M. (2018). Psychosocial safety climate as a moderator of the moderators: Contextualizing JDR models and emotional demands effects. J. Occup. Organ. Psychol. 91, 620-644. doi: 10.1111/joop. 12211

Loon, M., Otaye-Ebede, L., and Stewart, J. (2018). The paradox of employee psychological well-being practices: An integrative literature review and new directions for research. Int. J. Hum. Resource. Manag. 30, 156-187. doi: 10.1080/ 09585192.2018.1479877

Marchington, M. (2015). Analysing the forces shaping employee involvement and participation (EIP) at organisation level in liberal market economies (LMEs). Hum. Resour. Manag. J. 25, 1-18. doi: 10.1111/1748-8583.12065

Masterson, C., Sugiyama, K., and Ladge, J. (2021). The value of 21 st century workfamily supports: Review and cross-level path forward. J. Organ. Behav. 42, 118-138. doi: 10.1002/job.2442

Mearns, K., Hope, L., Ford, M. T., and Tetrick, L. E. (2010). Investment in workforce health: Exploring the implications for workforce safety climate and commitment. Accid Anal. Prev. 42, 1445-1454. doi: 10.1016/j.aap.2009. 08.009

Mendelson, M. B., Turner, N., and Barling, J. (2011). Perceptions of the presence and effectiveness of high involvement work systems and their relationship to employee attitudes: A test of competing models. Pers. Rev. 40, 45-69. doi: 10.1108/00483481111095519

Meyer, J. P., Allen, N. J., and Smith, C. A. (1993). Commitment to Organizations and Occupations: Extension and Test of a Three-Component Conceptualization. J. Appl. Psychol. 78, 538-551. doi: 10.1037/0021-9010.78.4. 538

Meyer, J. P., and Allen, N. J. (1991). A three-component conceptualization of organizational commitment. Hum. Resour. Manag. Rev. 1, 61-89. doi: 10.1016/ 1053-4822(91)90011-Z

Meyer, J. P., Stanley, D. J., Herscovitch, L., and Topolnytsky, L. (2002). Affective, Continuance, and Normative Commitment to the Organization: A Metaanalysis of Antecedents, Correlates, and Consequences. J. Vocat. Behav. 61, 20-52. doi: 10.1006/jvbe.2001.1842

Meyer, M. (2018). The Evolution and Challenges of the Concept of Organizational Virtuousness in Positive Organizational Scholarship. J. Bus. Ethics 153, 245-264. doi: 10.1007/s10551-016-3388-z

Moneta, G. B. (2017). Validation of the short flow in work scale (SFWS). Pers. Individ. Differ. 109, 83-88. doi: 10.1016/j.paid.2016.12.033

Morin, A. J. S., Arens, A. K., and Marsh, H. W. (2016). A Bifactor Exploratory Structural Equation Modeling Framework for the Identification of Distinct Sources of Construct-Relevant Psychometric Multidimensionality. Struct. Equ. Modeling 23, 116-139. doi: 10.1080/10705511.2014.961800

Murphy, K., Torres, E., Ingram, W., and Hutchinson, J. (2018). Review of highperformance work practices (HPWPs) literature and recommendations for future research in the hospitality industry. Int. J. Contemp. Hosp. Manag. 30, 365-388. doi: 10.1108/IJCHM-05-2016-0243
Nahrgang, J. D., Morgeson, F. P., and Hofmann, D. A. (2011). Safety at work: A meta-analytic investigation of the link between job demands, job resources, burnout, engagement, and safety outcomes. J. Appl. Psychol. 96, 71-94. doi: 10.1037/a0021484

Newman, A., Cooper, B., Holland, P., Miao, Q., and Teicher, J. (2018). How do industrial relations climate and union instrumentality enhance employee performance? The mediating effects of perceived job security and trust in management. Hum. Resour. Manage. 58, 35-44. doi: 10.1002/hrm.21921

Nielsen, M. B., Mearns, K., Matthiesen, S. B., and Eid, J. (2011). Using the Job Demands-Resources model to investigate risk perception, safety climate and job satisfaction in safety critical organizations. Scand. J. Psychol. 52, 465-475. doi: 10.1111/j.1467-9450.2011.00885.x

Nikandrou, I., and Tsachouridi, I. (2015). Towards a better understanding of the "buffering effects" of organizational virtuousness' perceptions on employee outcomes. Manag. Decis. 53, 1823-1842. doi: 10.1108/MD-06-2015-0251

Nunnally, J. (1978). Psychometric theory, 2nd Edn. New York, NY: McGraw Hill.

Ogbonnaya, C., Daniels, K., Connolly, S., and van Veldhoven, M. (2017). Integrated and isolated impact of high-performance work practices on employee health and well-being: A comparative study. J. Occup. Health Psychol. 22, 98-114. doi: $10.1037 /$ ocp0000027

Oppenauer, V., and Van De Voorde, K. (2016). Exploring the relationships between high involvement work system practices, work demands and emotional exhaustion: A multi-level study. Int. J. Hum. Resource Manag. 29, 311-337. doi: 10.1080/09585192.2016.1146321

Paré, G., and Tremblay, M. (2007). The Influence of High-Involvement Human Resources Practices, Procedural Justice, Organizational Commitment, and Citizenship Behaviors on Information Technology Professionals' Turnover Intentions. Group Organ. Manag. 32, 326-357. doi: 10.1177/10596011062 86875

Parker, A. W., Tones, M. J., and Ritchie, G. E. (2017). Development of a multilevel health and safety climate survey tool within a mining setting. J. Safety Res. 62, 173-180. doi: 10.1016/j.jsr.2017.06.007

Probst, T. M. (2005). Countering the Negative Effects of Job Insecurity Through Participative Decision Making: Lessons From the Demand-Control Model. J. Occup. Health Psychol. 10, 320-329. doi: 10.1037/1076-8998.10.4.320

Qiao, K., Khilji, S., and Wang, X. (2009). High-performance work systems, organizational commitment, and the role of demographic features in the People's Republic of China. Int. J. Hum. Resource Manag. 20, 2311-2330. doi: 10.1080/09585190903239682

Rabl, T., Jayasinghe, M., Gerhart, B., and Kühlmann, T. M. (2014). A metaanalysis of country differences in the high-performance work system-business performance relationship: The roles of national culture and managerial discretion. J. Appl. Psychol. 99, 1011-1041. doi: 10.1037/a0037712

Raineri, A. (2017). Linking human resources practices with performance: The simultaneous mediation of collective affective commitment and human capital. Int. J. Hum. Resource Manag. 28, 3149-3178. doi: 10.1080/09585192.2016. 1155163

Ramsay, H., Scholarios, D., and Harley, B. (2000). Employees and HighPerformance Work Systems: Testing inside the Black Box. Br. J. Ind. Relat. 38, 501-531. doi: 10.1111/1467-8543.00178

Rego, A., and Cunha, M. P. E. (2009). Do the opportunities for learning and personal development lead to happiness? It depends on work-family conciliation. J. Occup. Health Psychol. 14, 334-348. doi: 10.1037/a0014248

Robinson, M. A. (2018). Using multi-item psychometric scales for research and practice in human resource management: Multi-Item Psychometric Scales. Hum. Resour. Manage. 57, 739-750. doi: 10.1002/hrm.21852

Roche, A. (2014). La recherche-intervention comme révélatrice des dimensions des pratiques de reconnaissance dans les organisations. @GRH 13, 11-42. doi: 10.3917/grh.144.0011

Rouat, S., Troyano, V., Cuvillier, B., Bobillier-Chaumon, M.-E., and Sarnin, P. (2017). Comprendre les ressorts des pratiques organisationnelles en matière de prévention des risques psychosociaux par les acteurs de l'entreprise: Une recherche dans l'industrie de la chimie. Perspect. Interdiscipl. Travail Santé 19:2. doi: 10.4000/pistes.5157

Salas-Vallina, A., Alegre, J., and López-Cabrales, A. (2021). The challenge of increasing employees' well-being and performance: How human resource management practices and engaging leadership work together toward reaching this goal. Hum. Resour. Manage. 60, 333-347. 
Saridakis, G., Lai, Y., and Cooper, C. L. (2017). Exploring the relationship between HRM and firm performance: A meta-analysis of longitudinal studies. Hum. Resour. Manag. Rev. 27, 87-96. doi: 10.1016/j.hrmr.2016.09.005

Schmidt, J. A., and Pohler, D. M. (2018). Making stronger causal inferences: Accounting for selection bias in associations between high performance work systems, leadership, and employee and customer satisfaction. J. Appl. Psychol. 103, 1001-1018. doi: 10.1037/apl0000315

Schulz, H., Zacher, H., and Lippke, S. (2017). The Importance of Team Health Climate for Health-Related Outcomes of White-Collar Workers. Front. Psychol. 8:74. doi: 10.3389/fpsyg.2017.00074

Shin, D., Garmendia, A., Ali, M., Konrad, A. M., and Madinabeitia-Olabarria, D. (2020). HRM systems and employee affective commitment: The role of employee gender. Gend. Manag. 35, 189-210. doi: 10.1108/GM-04-2019-0053

Simard, G., Doucet, O., and Bernard, S. (2005). Pratiques en GRH et engagement des employés: Le rôle de la justice. Relat. Ind. 60, 296-319. doi: 10.7202/ 011723ar

Sison, A. J. G., and Ferrero, I. (2015). How different is neo-Aristotelian virtue from positive organizational virtuousness? Bus. Ethics 24, 78-98. doi: 10.1111/beer. 12099

Snape, E., and Redman, T. (2012). Industrial Relations Climate and Union Commitment: An Evaluation of Workplace-Level Effects. Ind. Relat. 51, 11-28. doi: 10.1111/j.1468-232X.2011.00662.x

Somech, A. (2010). Participative Decision Making in Schools: A MediatingModerating Analytical Framework for Understanding School and Teacher Outcomes. Educ. Adm. Q. 46, 174-209. doi: 10.1177/1094670510361745

Sousa-Lima, M., Michel, J. W., and Caetano, A. (2013). Clarifying the importance of trust in organizations as a component of effective work relationships: Trust in organizations. J. Appl. Soc. Psychol. 43, 418-427. doi: 10.1111/j.1559-1816.2013. 01012.x

Spector, P. E., Rosen, C. C., Richardson, H. A., Williams, L. J., and Johnson, R. E. (2019). A New Perspective on Method Variance: A Measure-Centric Approach. J. Manage. 45, 855-880. doi: 10.1177/0149206316687295

Spreitzer, G., Porath, C. L., and Gibson, C. B. (2012). Toward human sustainability. Organ. Dyn. 41, 155-162. doi: 10.1016/j.orgdyn.2012.01.009

Stajkovic, A. D., and Luthans, F. (2003). Behavioral management and task performance in organizations: Conceptual background, meta-analysis, and test of alternative models. Pers. Psychol. 56, 155-194. doi: 10.1111/j.1744-6570.2003. tb00147.x

Tabachnick, B. G., and Fidell, L. S. (2013). Using Multivariate Statistics, 6th Edn. Boston, MA: Pearson.

Tavani, J. L., Botella, M., and Collange, J. (2014). Quelle validité pour une mesure de la satisfaction au travail en un seul item? Prat. Psychol. 20, 125-142. doi: 10.1016/j.prps.2014.03.001

Thibaut, J. W., and Walker, L. (1975). Procedural Justice A Psychological Analysis. Hillsdale: L. Erlbaum Associates.

Topcic, M., Baum, M., and Kabst, R. (2016). Are high-performance work practices related to individually perceived stress? A job demands-resources perspective. T Int. J. Hum. Resource Manag. 27, 45-66. doi: 10.1080/09585192.2015.1043136

Tremblay, M., Guay, P., and Simard, G. (2000). L'engagement organisationnel et les comportements discrétionnaires: L'influence des pratiques de gestion des ressources humaines. CIRANO 24, 1-24.

Van Beurden, J., Van De Voorde, K., and Van Veldhoven, M. (2021). The employee perspective on HR practices: A systematic literature review, integration and outlook. Int. J. Hum. Resource. Manag. 32, 359-393. doi: 10.1080/09585192. 2020.1759671

Van De Voorde, K., Paauwe, J., and Van Veldhoven, M. (2012). Employee Wellbeing and the HRM-Organizational Performance Relationship: A Review of Quantitative Studies. Int. J. Manag. Rev. 14, 391-407. doi: 10.1111/j.1468-2370. 2011.00322.x

van Vuuren, M., de Jong, M. D. T., and Seydel, E. R. (2007). Direct and indirect effects of supervisor communication on organizational commitment. Corp. Comm. Int. J. 12, 116-128. doi: 10.1108/13563280710744801

Wang, Y., Kim, S., Rafferty, A., and Sanders, K. (2020). Employee perceptions of HR practices: A critical review and future directions. Int. J. Hum. Resource Manag. 31, 128-173. doi: 10.1080/09585192.2019.1674360

Wang, Z., Xing, L., and Zhang, Y. (2019). Do high-performance work systems harm employees' health? An investigation of service-oriented HPWS in the Chinese healthcare sector. Int. J. Hum. Resource. Manag. 32, 2264-2297. doi: $10.1080 / 09585192.2019 .1579254$
Weber, W. G., Unterrainer, C., and Höge, T. (2020). Psychological Research on Organisational Democracy: A Meta-Analysis of Individual, Organisational, and Societal Outcomes. Appl. Psychol. 69, 1009-1071. doi: 10.1111/apps.12205

West, M. A., Guthrie, J. P., Dawson, J. F., Borrill, C. S., and Carter, M. (2006). Reducing patient mortality in hospitals: The role of human resource management. J. Organ. Behav. 27, 983-1002. doi: 10.1002/job.396

Wilkinson, A., Gollan, P. J., Marchington, M., and Lewin, D. (2010). "Conceptualizing employee participation in organizations," in The Oxford Handbook of Participation in Organizations, eds A. Wilkinson, P. J. Gollan, M. Marchington, and D. Lewin (Oxford: Oxford University Press), 3-25.

Wilson, M. G., Dejoy, D. M., Vandenberg, R. J., Richardson, H. A., and Mcgrath, A. L. (2004). Work characteristics and employee health and well-being: Test of a model of healthy work organization. J. Occup. Organ. Psychol. 77, 565-588. doi: 10.1348/0963179042596522

Witt, L. A., Andrews, M. C., and Kacmar, K. M. (2000). The Role of Participation in Decision-Making in the Organizational Politics-Job Satisfaction Relationship. Hum. Relat. 53, 341-358. doi: 10.1177/0018726700533003

Wood, S., and de Menezes, L. M. (2011). High involvement management, highperformance work systems and well-being. Int. J. Hum. Resource. Manag. 22, 1586-1610. doi: 10.1080/09585192.2011.561967

World Medical Association (2013). World Medical Association Declaration of Helsinki: Ethical Principles for Medical Research Involving Human Subjects. JAMA 310, 2191-2194. doi: 10.1001/jama.2013.281053

Wright, P. M., and Nishii, L. H. (2006). Strategic HRM and Organizational Behavior: Integrating Multiple Levels of Analysis. Technical Report 07-03, Ithaca, NY: CAHRS at Cornell University, 43-66.

Yoerger, M., Crowe, J., and Allen, J. A. (2015). Participate or else!: The effect of participation in decision-making in meetings on employee engagement. Consult. Psychol. J. 67, 65-80. doi: 10.1037/cpb0000029

Zhang, H., and Agarwal, N. C. (2009). The mediating roles of organizational justice on the relationships between HR practices and workplace outcomes: An investigation in China. Int. J. Hum. Resource. Manag. 20, 676-693. doi: $10.1080 / 09585190802707482$

Zhang, J., Bal, P. M., Akhtar, M. N., Long, L., Zhang, Y., and Ma, Z. (2018). Highperformance work system and employee performance: The mediating roles of social exchange and thriving and the moderating effect of employee proactive personality. Asia Pac. J. Hum. Resour. 57, 369-395. doi: 10.1111/1744-7941. 12199

Zhang, M., Zhu, C. J., Dowling, P. J., and Bartram, T. (2013). Exploring the effects of high-performance work systems (HPWS) on the work-related well-being of Chinese hospital employees. Int. J. Hum. Resource. Manag. 24, 3196-3212. doi: 10.1080/09585192.2013.775026

Zhou, Y., Lemmer, G., Xu, J., and Rief, W. (2019). Cross-Cultural Measurement Invariance of Scales Assessing Stigma and Attitude to Seeking Professional Psychological Help. Front. Psychol. 10:1249. doi: 10.3389/fpsyg.2019. 01249

Zweber, Z. M., Henning, R. A., and Magley, V. J. (2016). A practical scale for MultiFaceted Organizational Health Climate Assessment. J. Occup. Health Psychol. 21, 250-259. doi: 10.1037/a0039895

\section{Conflict of Interest: FL headed AD Conseil.}

The remaining authors declare that the research was conducted in the absence of any business or financial relationship that could be construed as a potential conflict of interest.

Publisher's Note: All claims expressed in this article are solely those of the authors and do not necessarily represent those of their affiliated organizations, or those of the publisher, the editors and the reviewers. Any product that may be evaluated in this article, or claim that may be made by its manufacturer, is not guaranteed or endorsed by the publisher.

Copyright (C) 2021 Aubouin-Bonnaventure, Fouquereau, Coillot, Lahiani and Chevalier. This is an open-access article distributed under the terms of the Creative Commons Attribution License (CC BY). The use, distribution or reproduction in other forums is permitted, provided the original author(s) and the copyright owner(s) are credited and that the original publication in this journal is cited, in accordance with accepted academic practice. No use, distribution or reproduction is permitted which does not comply with these terms. 